\title{
Lower Serum Androstenedione Levels in Pre-Rheumatoid Arthritis versus Normal Control Women: Correlations with Lower Serum Cortisol Levels
}

\author{
Alfonse T. Masi, ${ }^{1}$ Kevin B. Elmore, ${ }^{2}$ Azeem A. Rehman, ${ }^{2}$ Robert T. Chatterton, ${ }^{3}$ \\ Ned J. Goertzen, ${ }^{2}$ and Jean C. Aldag ${ }^{2}$ \\ ${ }^{1}$ Department of Medicine, University of Illinois College of Medicine (UICOMP), One Illini Drive, Peoria, IL 61656, USA \\ ${ }^{2}$ University of Illinois College of Medicine at Peoria, Peoria, IL 61656, USA \\ ${ }^{3}$ Northwestern University (NWU), Feinberg School of Medicine, Chicago, IL 60611, USA
}

Correspondence should be addressed to Alfonse T. Masi; amasi@uic.edu

Received 28 February 2013; Accepted 23 April 2013

Academic Editor: Daniela Melchiorre

Copyright ( 2013 Alfonse T. Masi et al. This is an open access article distributed under the Creative Commons Attribution License, which permits unrestricted use, distribution, and reproduction in any medium, provided the original work is properly cited.

\begin{abstract}
Serum adrenal androgens (AAs), including androstenedione $(\triangle 4 \mathrm{~A})$ and dehydroepiandrosterone sulfate (DHEAS), have been reported to be lower in female rheumatoid arthritis (RA) patients with early disease. Few data are available on hormonal status of women before the onset of clinical rheumatoid arthritis (pre-RA). A broad baseline panel of serum adrenal and sex steroids was compared in 36 female pre-RA to 144 matched cohort control $(\mathrm{CN})$ subjects to determine differences in their mean values and in patterns of hormonal correlations. Study subjects having lower versus higher baseline serum cortisol levels than the total group's mean value were also analyzed separately to investigate differences in their hormonal levels and correlational patterns. In total subjects, mean $( \pm \mathrm{SE}) \Delta 4 \mathrm{~A}$ level $(\mathrm{nmol} / \mathrm{L})$ was lower $(P=0.018)$ in 28 pre-RA cases $(6.4 \pm 0.40)$ versus $108 \mathrm{CN}(7.8 \pm 0.28)$. The significant $(P=0.013)$ difference was restricted to 9 pre-RA versus $53 \mathrm{CN}$ subjects having lower cortisol levels $(5.6 \pm 0.73$ versus $8.0 \pm 0.42 \mathrm{nmol} / \mathrm{L}$, resp.). In total subjects, no significant difference was found between study subjects in their bivariate correlations of the hormonal panel variables, unlike results found in the subgroups stratified by lower versus higher cortisol levels. A subgroup of pre-RA females may have relative adrenal cortical insufficiency, as reflected by lower $\Delta 4 \mathrm{~A}$, especially observed among those subjects with lower cortisol levels.
\end{abstract}

\section{Introduction}

Relative insufficiency of adrenal glucocorticoid (GC) and androgenic-anabolic (AA) hormones has been suspected to increase the risk of developing rheumatoid arthritis (RA) and to contribute to its multifactorial neuroendocrine immune (NEI) pathogenesis [1-8]. The characteristic age- and sexspecific incidence patterns of RA support a possible constitutional deficiency of adrenal cortical or sex hormones in a subset of susceptible women. The female-to-male (F:M) risk ratio of persons developing RA is approximately $2: 1$ during the juvenile and older ages but is significantly increased to about $5: 1$ during the female reproductive years [9]. Of further note, risk of RA onset increases with age in adults, particularly among females. The preceding risk data imply that males have relative protection over females during all ages, but particularly in the younger and middle adult years [9]. A recent study indicated that early age at menopause $(\leq 45$ years) was associated with the subsequent risk of developing RA [10]. The hazard remained significant after adjusting for smoking, educational level, and length of breastfeeding [10]. Available data imply that the woman's risk of developing RA may be affected by relative insufficiency of both adrenal cortical GC and AA steroids as well as by accelerated aging of their ovarian hormonal status [1-10].

A quantitative study of adrenal steroid urinary metabolites from 8 early disease premenopausal RA women not treated with GC drugs and 8 healthy matched controls under varied baseline, physiological adrenal stimulation, and metyrapone GC-inhibiting conditions supported AA deficiency in 
the patients [11]. Significant differences were found only in the 11-deoxy-17-ketosteroid AA steroids: dehydroepiandrosterone (DHEA), androsterone, and etiocholanolone [11]. Subsequent studies of serum DHEA and its sulfate (DHEAS) in early disease premenopausal onset women found lower mean levels of these AA biomarkers than in matched controls $[5,8,12,13]$. A nested case-control cohort study showed that definitely low baseline serum DHEAS levels $(<0.68 \mu \mathrm{mol} / \mathrm{L})$, assayed in independent reference laboratories, were present a mean of 11 years before premenopausal onset in $3(30 \%)$ of 10 pre-RA versus $1(2.7 \%)$ of 37 matched $\mathrm{CN}$ subjects $(P=$ $0.026)$ [14]. Recently, the same cohort study [15] revealed that definitely low baseline serum cortisol levels had occurred in a greater minority of pre-RA than $\mathrm{CN}$ females (11\% versus $1.4 \%$, resp., $P=0.016)$. In addition, none of 28 pre-RA women had serum androstenedione $(\triangle 4 \mathrm{~A})$ levels in the upper normal range $(\geq 7.5 \mathrm{nmol} / \mathrm{L})$ versus $26(24 \%)$ of $108 \mathrm{CN}$ women $(P=$ 0.010 ). The lower levels of urinary AA metabolites, serum DHEA, and DHEAS in premenopausal early RA patients and the recent findings of baseline lower serum cortisol, as well as a truncated upper range of $\Delta 4 \mathrm{~A}$ levels in a minority of pre-RA versus $\mathrm{CN}$ female cohort subjects, have prompted this further analysis of a comprehensive panel of adrenal cortical and sex steroids in our pre-RA and CN cohort subjects $[15,16]$.

\section{Materials and Methods}

2.1. The RA Precursors Study (RAPS) Database at This Institution. The RA Precursors Study (RAPS) was initiated at this institution in late 1991, following donation of baseline personal data and serum samples from the pre-RA cases and matched CN cohort subjects by "Operation CLUE I," a community-wide prospective study [19-21]. The 1974 CLUE I base cohort had enrolled 12,381 females of Washington County, Maryland, USA. The RAPS female database currently includes 180 study subjects, 36 Caucasian pre-symptomatic RA (pre-RA) cases at their 1974 baseline entry, and 144 matched cohort CN subjects, in a ratio of 1 pre-RA: $4 \mathrm{CN}$. The UICOMP Institutional Review Board has approved this research for assurance of confidentiality.

The pre-RA cases in this study conform to The European League Against Rheumatism (EULAR) recommendations [22]. All baseline pre-RA cases were diagnosed and confirmed in the practice of the sole rheumatologist in the cohort community, who used the American College of Rheumatology (ACR) 1987 revised classification criteria [23]. Following the 1974 cohort entry, clinical onsets of RA in our study females occurred within 3 to 18 years (1977 to 1992), after a median of 11 years. None of the matched comparison subjects had a diagnosis of RA in the community rheumatologist's practice. The non-RA subjects $(\mathrm{CN})$ were matched to the preRA cases on race (all Caucasians) and usually within one year of age at entry. Also, the $\mathrm{CN}$ subjects were the closest in chronological sequence of enrollment in the cohort, analogous to another case-control study [24].

In 1992, after clinical onset and diagnosis of the first set of baseline pre-RA females, 4 cohort $\mathrm{CN}$ subjects were matched to each female case on entry age and sex to permit more specific search for hormonal determinants of RA, other than those already known demographic risk factors $[9,25]$. Case or control subjects who had known cancer diagnoses during follow-up were excluded from the RAPS database. Their sera were reserved to study cancer biomarkers, which is the primary purpose of Operation CLUE [19-21].

\subsection{The Hormonal Reference Laboratory Performed Assays, in} 1992 and 1994 (Table 1). The mean concentrations of the original reported assays performed by the referral laboratory in the first 1992 and second 1994 sets of subjects are indicated in Table 1, as well as other statistical values. The baseline-stored $\left(-70^{\circ} \mathrm{C}\right)$ cohort sera were always analyzed in matched sets of 1 pre-RA and $4 \mathrm{CN}$, without knowledge of subject status. As funding was secured during the interval of 1992 to 1994, the first (1992) and second (1994) sets of study subjects' sera were sequentially donated by project CLUE for the hormonal assays in the referral laboratory. The first set of study subjects were 14 baseline pre-RA and $56 \mathrm{CN}$ females. Their frozen sera were sent by CLUE to the Immunoassay Core Facility at Northwestern University (NWU) for hormonal assays in 1992 [16]. One subject had no sera available, but the other 69 had mostly sufficient sera to assay the full panel of hormones; a limited number lacked DHEA $(n=6), \Delta 4 \mathrm{~A}(n=5)$, and testosterone $(n=9)$ assays (Table 1$)$. Serum estrone levels were only assayed in the first set females. The second set of female cohort subjects were 22 pre-RA and $88 \mathrm{CN}$ subjects, whose frozen sera were sent from CLUE I to the NWU laboratory, in 1994. Those sera were sufficient to perform 4 hormonal tests completely (corticosterone, deoxycortisol, cortisol, and DHEAS) or almost completely (progesterone) (Table 2). Also, they were shared with other laboratories which performed immunological assays [16]. Two-thirds of the other tests were completed, but one-half of estradiol assays, which had the lowest concentrations, requiring greater amount of sera.

\subsection{Specific Assays Were Developed for a Comprehensive} Panel of Serum Steroids (Figure 1). A comprehensive panel of adrenal and sex steroids were assayed (Figure 1) using a procedure developed specifically for this study to permit measurements of 12 steroids in duplicate from $1 \mathrm{~mL}$ of serum. The fractionation procedure permitted assay of each steroid in greater sensitivity than would otherwise be detectable without fractionation. The method also provided an additional purification step, adding to the specificity of the procedure.

Serum $(1.0 \mathrm{~mL})$ was diluted by addition of $1.0 \mathrm{~mL}$ of $4 \mathrm{M}$ urea. ${ }^{3} \mathrm{H}$-tracers $(5,000 \mathrm{cpm})$ of representative steroids, estrone (E1), testosterone ( $\mathrm{T})$, and progesterone (prog), were added and the solution was heated for $30 \mathrm{~min}$ at $60^{\circ} \mathrm{C}$ to denature the protein. Steroids were extracted by the use of an ODS cartridge (SepPak, Millipore, Inc., Billerica, MA). The cartridge was washed with $3 \mathrm{~mL}$ methanol followed by $6 \mathrm{~mL}$ of distilled water. The serum was aspirated through the cartridge. Retention of the steroids was complete, as negligible loss of the ${ }^{3} \mathrm{H}$-tracers into the effluent had occurred. A $7 \mathrm{~mL}$ of water wash was discarded, and the conjugated steroids (androstanediol glucuronide and DHEAS) were eluted with $10 \mathrm{~mL}$ of $47 \%$ aqueous methanol (Fraction A1). The second fraction was eluted with $12 \mathrm{~mL}$ of $60 \%$ aqueous methanol 
TABLE 1: Hormones reported by the referral laboratory in a first (1992) and second (1994) set of assays.

\begin{tabular}{|c|c|c|c|c|c|c|}
\hline \multirow{2}{*}{$\begin{array}{l}\text { Hormones assayed and } \\
\text { statistical values }\end{array}$} & \multicolumn{3}{|c|}{ Reported assay results in 1st and 2 nd female sets } & \multicolumn{3}{|c|}{ Normalized combined assays } \\
\hline & 1st Set & 2nd Set & All females & Control & Pre-RA & All females \\
\hline \multicolumn{7}{|l|}{ Pregnenolone: } \\
\hline Mean $(\mathrm{nmol} / \mathrm{L}) \pm \operatorname{SE}(n)$ & $5.3 \pm 0.57(69)$ & $5.2 \pm 0.32(73)^{*}$ & $5.3 \pm 0.32(142)$ & $5.1 \pm 0.34(111)$ & $5.6 \pm 0.88(31)$ & $5.2 \pm 0.32(142)$ \\
\hline Median; IQR & $3.1 ; 2.70-5.56$ & $4.6 ; 3.57-6.95$ & $3.9 ; 3.11-6.50$ & $3.8 ; 2.67-6.59$ & $3.95 ; 3.29-6.06$ & $3.8 ; 2.93-6.57$ \\
\hline \multicolumn{7}{|l|}{ Progesterone: } \\
\hline Mean $(\mathrm{nmol} / \mathrm{L}) \pm \operatorname{SE}(n)$ & $5.8 \pm 1.26(69)$ & $14.0 \pm 2.02(107)$ & $10.8 \pm 1.35(176)$ & $13.4 \pm 1.49(141)$ & $17.3 \pm 3.37(35)$ & $14.2 \pm 1.37(176)$ \\
\hline Median; IQR & $0.0 ; 0.00-9.79$ & $3.9 ; 1.88-19.4$ & $2.9 ; 0.00-11.5$ & $5.8 ; 2.10-16.1$ & $5.0 ; 2.10-30.1$ & $5.7 ; 2.10-19.3$ \\
\hline \multicolumn{7}{|l|}{ 17-OH Pregnenolone: } \\
\hline Mean $(\mathrm{nmol} / \mathrm{L}) \pm \operatorname{SE}(n)$ & $5.1 \pm 0.40(69)$ & $7.2 \pm 0.57(73)$ & $6.2 \pm 0.36(142)$ & $7.2 \pm 0.41(111)$ & $7.0 \pm 0.71(31)$ & $7.1 \pm 0.35(142)$ \\
\hline Median; IQR & $4.4 ; 2.50-7.34$ & $5.6 ; 4.21-9.45$ & $5.1 ; 3.34-7.96$ & $5.9 ; 4.33-9.27$ & $5.9 ; 3.82-8.90$ & $6.0 ; 4.30-9.26$ \\
\hline \multicolumn{7}{|l|}{ 17-OH Progesterone: } \\
\hline Mean $(\mathrm{nmol} / \mathrm{L}) \pm \operatorname{SE}(n)$ & $3.8 \pm 0.36(69)$ & $4.8 \pm 0.53(73)^{*}$ & $4.3 \pm 0.33(142)$ & $4.8 \pm 0.39(111)$ & $4.5 \pm 0.60(31)$ & $4.7 \pm 0.33(142)$ \\
\hline Median; IQR & $2.6 ; 1.66-5.58$ & $3.4 ; 1.60-6.27$ & $2.8 ; 1.63-5.85$ & $3.2 ; 1.93-6.35$ & $3.6 ; 1.57-6.93$ & $3.5 ; 1.93-6.38$ \\
\hline \multicolumn{7}{|l|}{ Dehydroepiandrosterone: } \\
\hline $\operatorname{Mean}(\mathrm{nmol} / \mathrm{L}) \pm \operatorname{SE}(n)$ & $11.5 \pm 1.04(63)$ & $19.8 \pm 1.78(73)$ & $15.9 \pm 1.12(136)$ & $20.2 \pm 1.23(107)$ & $18.0 \pm 2.18(29)$ & $19.7 \pm 1.07(136)$ \\
\hline Median; IQR & $9.1 ; 5.28-17.4$ & $15.9 ; 12.5-19.3$ & $13.4 ; 8.63-18.4$ & $16.9 ; 13.4-25.0$ & $15.5 ; 12.0-17.8$ & $16.3 ; 13.1-21.8$ \\
\hline \multicolumn{7}{|l|}{ Androstenedione: } \\
\hline Mean $(\mathrm{nmol} / \mathrm{L}) \pm \operatorname{SE}(n)$ & $7.5 \pm 0.45(64)$ & $3.2 \pm 0.27(72)$ & $5.2 \pm 0.32(136)$ & $7.8 \pm 0.28(108)$ & $6.4 \pm 0.40(28)^{\dagger}$ & $7.5 \pm 0.24(136)$ \\
\hline Median; IQR & $6.7 ; 4.90-10.4$ & $2.8 ; 1.71-4.16$ & $4.2 ; 2.23-7.25$ & $7.2 ; 5.91-9.53$ & $6.5 ; 4.99-7.88$ & $7.1 ; 5.55-8.97$ \\
\hline \multicolumn{7}{|l|}{ Testosterone: } \\
\hline Mean $(\mathrm{nmol} / \mathrm{L}) \pm \mathrm{SE}(n)$ & $0.89 \pm 0.05(60)$ & $2.5 \pm 0.21(73)$ & $1.8 \pm 0.13(133)$ & $2.5 \pm 0.14(103)$ & $2.5 \pm 0.21(30)$ & $2.5 \pm 0.12(133)$ \\
\hline Median; IQR & $0.83 ; 0.56-1.11$ & $2.3 ; 1.39-3.35$ & $1.3 ; 0.76-2.34$ & $2.4 ; 1.80-3.03$ & $2.3 ; 1.84-2.89$ & $2.4 ; 1.81-2.95$ \\
\hline \multicolumn{7}{|l|}{ Estradiol: } \\
\hline Mean $(\mathrm{pmol} / \mathrm{L}) \pm \mathrm{SE}(n)$ & $562 \pm 29(69)$ & $263 \pm 42.3(61)$ & $422 \pm 28(130)$ & $253 \pm 24(102)$ & $247 \pm 43(28)$ & $252 \pm 21(130)$ \\
\hline Median; IQR & $518 ; 435-659$ & $159 ; 75-315$ & $386 ; 175-568$ & $202 ; 96-329$ & $181 ; 108-367$ & $191 ; 98-340$ \\
\hline \multicolumn{7}{|l|}{ Estrone: } \\
\hline Mean $(\mathrm{pmol} / \mathrm{L}) \pm \operatorname{SE}(n)$ & $282 \pm 43(69)$ & Not performed & $283 \pm 43(69)$ & $289 \pm 53(55)$ & $216 \pm 35(14)$ & $274 \pm 43(69)$ \\
\hline Median; IQR & $209 ; 146-309$ & & $209 ; 146-309$ & $201 ; 140-301$ & $182 ; 122-297$ & $201 ; 137.0-300$ \\
\hline \multicolumn{7}{|l|}{ Corticosterone (cmpd B): } \\
\hline $\operatorname{Mean}(\mathrm{nmol} / \mathrm{L}) \pm \operatorname{SE}(n)$ & $10.2 \pm 0.85(69)$ & $1.63 \pm 0.17(110)$ & $5.0 \pm 0.47(179)$ & $10.5 \pm 0.40(143)$ & $9.6 \pm 0.64(36)$ & $10.3 \pm 0.34(179)$ \\
\hline Median; IQR & $8.00 ; 6.23-12.8$ & $1.18 ; 0.45-2.00$ & $2.28 ; 0.92-7.36$ & $9.60 ; 8.56-11.0$ & $9.54 ; 7.76-10.7$ & $9.60 ; 8.56-10.9$ \\
\hline \multicolumn{7}{|l|}{ Deoxycortisol: } \\
\hline Mean $(\mathrm{nmol} / \mathrm{L}) \pm \operatorname{SE}(n)$ & $2.3 \pm 0.18(69)$ & $0.49 \pm 0.09(110)$ & $1.2 \pm 0.11(179)$ & $2.3 \pm 0.10(143)$ & $2.2 \pm 0.17(36)$ & $2.3 \pm 0.09(179)$ \\
\hline Median; IQR & $2.2 ; 1.07-3.15$ & $0.25 ; 0.00-0.67$ & $0.64 ; 0.12-1.85$ & $2.2 ; 1.6-2.7$ & $2.1 ; 1.57-2.93$ & $2.2 ; 1.6-2.7$ \\
\hline \multicolumn{7}{|l|}{ Cortisol: } \\
\hline $\operatorname{Mean}(\mathrm{nmol} / \mathrm{L}) \pm \operatorname{SE}(n)$ & $280.0 \pm 17(69)$ & $236.4 \pm 12(110)$ & $253.1 \pm 10(179)$ & $233.7 \pm 11(143)$ & $245.2 \pm 24(36)$ & $236.0 \pm 9.9(179)$ \\
\hline Median; IQR & $250.8 ; 189-327$ & $218.1 ; 148-286$ & $232.0 ; 164-309$ & $206.1 ; 155-285$ & $240.5 ; 143-329$ & $217.4 ; 154-286$ \\
\hline \multicolumn{7}{|l|}{ DHEA sulfate (DHEAS): } \\
\hline Mean $(\mu \mathrm{mol} / \mathrm{L}) \pm \operatorname{SE}(n)$ & $2.9 \pm 0.27 ;(69)$ & $1.9 \pm 0.14(110)$ & $2.4 \pm 0.14(179)$ & $2.9 \pm 0.16(143)$ & $2.5 \pm 0.26(36)$ & $2.9 \pm 0.14(179)$ \\
\hline Median; IQR & $2.4 ; 1.24-4.20$ & $1.8 ; 1.04-2.63$ & $1.9 ; 1.10-3.08$ & $2.6 ; 1.63-3.86$ & $2.3 ; 1.53-3.50$ & $2.5 ; 1.59-3.83$ \\
\hline Mean ages \pm SEs & $43.7 \pm 1.2$ & $44.0 \pm 1.2$ & $43.9 \pm 0.89$ & $43.9 \pm 0.99$ & $43.8 \pm 2.03$ & $43.9 \pm 0.89$ \\
\hline
\end{tabular}

SE: standard error of mean; IQR: interquartile range of median.

${ }^{*}$ Mean steroid values which did not differ $(P>0.050)$ between sets (see text for details). ${ }^{\dagger} P=0.018$. 
TABLE 2: Normalized assays in CN and Pre-RA Subjects having lower versus higher cortisol values than the total female mean.

\begin{tabular}{|c|c|c|c|c|c|c|}
\hline \multirow{2}{*}{$\begin{array}{l}\text { Hormones assayed and } \\
\text { statistical values }\end{array}$} & \multicolumn{3}{|c|}{ Normalized assays in low cortisol females } & \multicolumn{3}{|c|}{ Normalized assays in high cortisol females } \\
\hline & Control & Pre-RA & Total & Control & Pre-RA & Total \\
\hline \multicolumn{7}{|l|}{ Pregnenolone: } \\
\hline Mean $(\mathrm{nmol} / \mathrm{L}) \pm \mathrm{SE}(n)$ & $5.1 \pm 0.49(54)$ & $4.9 \pm 1.08(10)$ & $5.1 \pm 0.44(64)$ & $5.1 \pm 0.47(57)$ & $5.9 \pm 1.20(21)$ & $5.3 \pm 0.47(78)$ \\
\hline Median; IQR & $4.0 ; 2.88-6.05$ & $3.8 ; 2.87-6.18$ & $3.9 ; 2.96-5.79$ & $3.6 ; 2.61-7.08$ & $4.2 ; 3.47-6.49$ & $3.8 ; 2.87-6.94$ \\
\hline \multicolumn{7}{|l|}{ Progesterone: } \\
\hline $\operatorname{Mean}(\mathrm{nmol} / \mathrm{L}) \pm \mathrm{SE}(n)$ & $12.4 \pm 1.9(71)$ & $18.3 \pm 7.10(12)$ & $13.2 \pm 1.98(83)$ & $14.5 \pm 2.22(70)$ & $16.8 \pm 3.68(23)$ & $15.0 \pm 1.90(93)$ \\
\hline Median; IQR & $5.5 \pm 2.10-13.6$ & $4.7 ; 2.10-36.2$ & $4.8 ; 2.10-16.2$ & $5.9 ; 2.15-17.0$ & $12.7 ; 2.77-30.1$ & $6.1 ; 2.29-22.5$ \\
\hline \multicolumn{7}{|l|}{ 17-OH Pregnenolone: } \\
\hline Mean $(n m o l / L) \pm \operatorname{SE}(n)$ & $6.9 \pm 0.60(54)$ & $5.7 \pm 0.74(10)$ & $6.7 \pm 0.52(64)$ & $7.5 \pm 0.55(57)$ & $7.5 \pm 0.98(21)$ & $7.5 \pm 0.48(78)$ \\
\hline Median; IQR & $5.7 ; 4.49-8.74$ & $6.1 ; 2.97-7.89$ & $5.8 ; 4.33-8.12$ & $6.7 ; 4.26-9.84$ & $5.7 ; 4.17-9.58$ & $6.0 ; 4.27-9.78$ \\
\hline \multicolumn{7}{|l|}{ 17-OH Progesterone: } \\
\hline $\operatorname{Mean}(\mathrm{nmol} / \mathrm{L}) \pm \mathrm{SE}(n)$ & $4.7 \pm 0.49(54)$ & $4.9 \pm 1.12(10)$ & $4.7 \pm 0.45(64)$ & $4.9 \pm 0.61(57)$ & $4.3 \pm 0.72(21)$ & $4.8 \pm 0.48(78)$ \\
\hline Median; IQR & $3.22 ; 1.98-6.50$ & $4.34 ; 1.55-7.77$ & $3.51 ; 1.95-7.00$ & $3.23 ; 1.78-6.16$ & $3.51 ; 1.70-6.11$ & $3.45 ; 1.86-6.10$ \\
\hline \multicolumn{7}{|l|}{ Dehydroepiandrosterone: } \\
\hline Mean $(\mathrm{nmol} / \mathrm{L}) \pm \mathrm{SE}(n)$ & $19.8 \pm 1.88(52)$ & $14.0 \pm 1.06(10)$ & $18.9 \pm 1.60(62)$ & $20.5 \pm 1.62(55)$ & $20.1 \pm 3.21(19)$ & $20.4 \pm 1.45(74)$ \\
\hline Median; IQR & $16.9 ; 13.5-21.8$ & $14.2 ; 11.9-17.4$ & $16.5 ; 12.5-19.9$ & $16.2 ; 13.4-26.1$ & $16.1 ; 11.5-20.9$ & $16.1 ; 13.2-26.0$ \\
\hline \multicolumn{7}{|l|}{ Androstenedione: } \\
\hline Mean $(\mathrm{nmol} / \mathrm{L}) \pm \mathrm{SE}(n)$ & $8.0 \pm 0.42(53)$ & $5.6 \pm 0.73(9)^{*}$ & $7.7 \pm 0.39(62)$ & $7.6 \pm 0.38(55)$ & $6.7 \pm 0.47(19)$ & $7.4 \pm 0.31(74)$ \\
\hline Median; IQR & $7.2 ; 6.20-9.69$ & $6.6 ; 3.85-6.87$ & $7.1 ; 6.12-9.00$ & $7.2 ; 5.63-9.54$ & $6.4 ; 5.18-8.65$ & $7.1 ; 5.42-8.88$ \\
\hline \multicolumn{7}{|l|}{ Testosterone: } \\
\hline Mean $(\mathrm{nmol} / \mathrm{L}) \pm \mathrm{SE}(n)$ & $2.7 \pm 0.22(51)$ & $2.5 \pm 0.33(10)$ & $2.7 \pm 0.19(61)$ & $2.3 \pm 0.16(52)$ & $2.4 \pm 0.28(20)$ & $2.3 \pm 0.14(72)$ \\
\hline Median; IQR & $2.4 ; 2.02-3.13$ & $2.3 ; 1.79-3.09$ & $2.4 ; 2.02-3.04$ & $2.3 ; 1.67-2.99$ & $2.2 ; 1.82-2.90$ & $2.3 ; 1.73-2.91$ \\
\hline \multicolumn{7}{|l|}{ Estradiol: } \\
\hline Mean $(\mathrm{pmol} / \mathrm{L}) \pm \mathrm{SE}(n)$ & $283 \pm 32(52) \dagger$ & $215 \pm 105(10)$ & $272 \pm 31(62)$ & $222 \pm 34(50)$ & $265 \pm 35(18)^{\dagger}$ & $233 \pm 27(68)$ \\
\hline Median; IQR & $221 ; 133-335$ & $128 ; 3.9-251$ & $214 ; 113-296$ & $139 ; 56-328$ & $195 ; 152-414$ & $175 ; 62-354$ \\
\hline \multicolumn{7}{|l|}{ Estrone: } \\
\hline Mean $(\mathrm{pmol} / \mathrm{L}) \pm \mathrm{SE}(n)$ & $330 \pm 102(28)$ & $127 \pm 27.3(5)$ & $299 \pm 87.2(33)$ & $246 \pm 26.9(27)$ & $265 \pm 44.3(9)^{*}$ & $251 \pm 22.7(36)$ \\
\hline Median; IQR & $199 ; 135-293$ & $141 ; 65-182$ & $195 ; 120-274$ & $208 ; 141-330$ & $269 ; 134-366$ & 218.; 141-353 \\
\hline \multicolumn{7}{|l|}{ Corticosterone (cmpd B): } \\
\hline Mean $(n m o l / L) \pm \operatorname{SE}(n)$ & $9.3 \pm 0.3(72)$ & $7.3 \pm 0.9(12)$ & $9.1 \pm 0.3(84)$ & $11.7 \pm 0.7(71)^{\ddagger}$ & $10.7 \pm 0.8(24)^{*}$ & $11.4 \pm 0.6(95)^{\ddagger}$ \\
\hline Median; IQR & $9.2 ; 8.35-10.3$ & $9.0 ; 4.43-9.64$ & $9.2 ; 8.19-10.1$ & $10.2 ; 9.01-12.8$ & $10.1 ; 8.91-11.6$ & $10.2 ; 8.95-12.4$ \\
\hline \multicolumn{7}{|l|}{ Deoxycortisol: } \\
\hline Mean $(\mathrm{nmol} / \mathrm{L}) \pm \mathrm{SE}(n)$ & $2.3 \pm 0.13(72)$ & $2.1 \pm 0.29(12)$ & $2.3 \pm 0.12(84)$ & $2.2 \pm 0.16(71)$ & $2.2 \pm 0.22(24)$ & $2.2 \pm 0.13(95)$ \\
\hline Median; IQR & $2.3 ; 1.69-2.63$ & $2.0 ; 1.57-3.02$ & $2.3 ; 1.65-2.63$ & $2.0 ; 1.55-2.66$ & $2.2 ; 1.57-2.93$ & $2.0 ; 1.55-2.66$ \\
\hline \multicolumn{7}{|l|}{ Cortisol: } \\
\hline $\operatorname{Mean}(\mathrm{nmol} / \mathrm{L}) \pm \mathrm{SE}(n)$ & $145.0 \pm 5.7(72)$ & $102.5 \pm 14.7(12)$ & $138.9 \pm 5.5(84)$ & $323.7 \pm 14.9(71)$ & $316.5 \pm 23.7(24)$ & $321.9 \pm 12.6(95)$ \\
\hline Median; IQR & $156 ; 111-179$ & $113.6 ; 51-146$ & $148.0 ; 105-174$ & $285.3 ; 241-351$ & $280.3 ; 237-375$ & $285.3 ; 241-361$ \\
\hline \multicolumn{7}{|l|}{ DHEA sulfate (DHEAS): } \\
\hline Mean $(\mu \mathrm{mol} / \mathrm{L}) \pm \mathrm{SE}(n)$ & $3.0 \pm 0.24(72)$ & $2.1 \pm 0.50(12)$ & $2.9 \pm 0.22(84)$ & $2.9 \pm 0.21(71)$ & $2.6 \pm 0.30(24)$ & $2.8 \pm 0.17(95)$ \\
\hline Median; IQR & $2.53 ; 1.70-3.73$ & $1.8 ; 0.79-4.02$ & $2.5 ; 1.58-3.73$ & $2.6 ; 1.59-3.99$ & $2.3 ; 1.60-3.49$ & $2.4 ; 1.59-3.91$ \\
\hline Mean ages \pm SEs $^{\ddagger}$ & $43.3 \pm 1.4$ & $44.6 \pm 3.4$ & $43.5 \pm 1.3$ & $44.6 \pm 1.4$ & $43.4 \pm 2.5$ & $44.3 \pm 1.2$ \\
\hline
\end{tabular}

SE: standard error of mean; IQR: interquartile range of median.

${ }^{*} P \leq 0.050 ;{ }^{\dagger} \mathrm{P} \leq 0.010 ;{ }^{\ddagger} \mathrm{P} \leq 0.001$ (see text for noncortisol differences between low versus high females and in pre-RA versus $\mathrm{CN}$ ). 


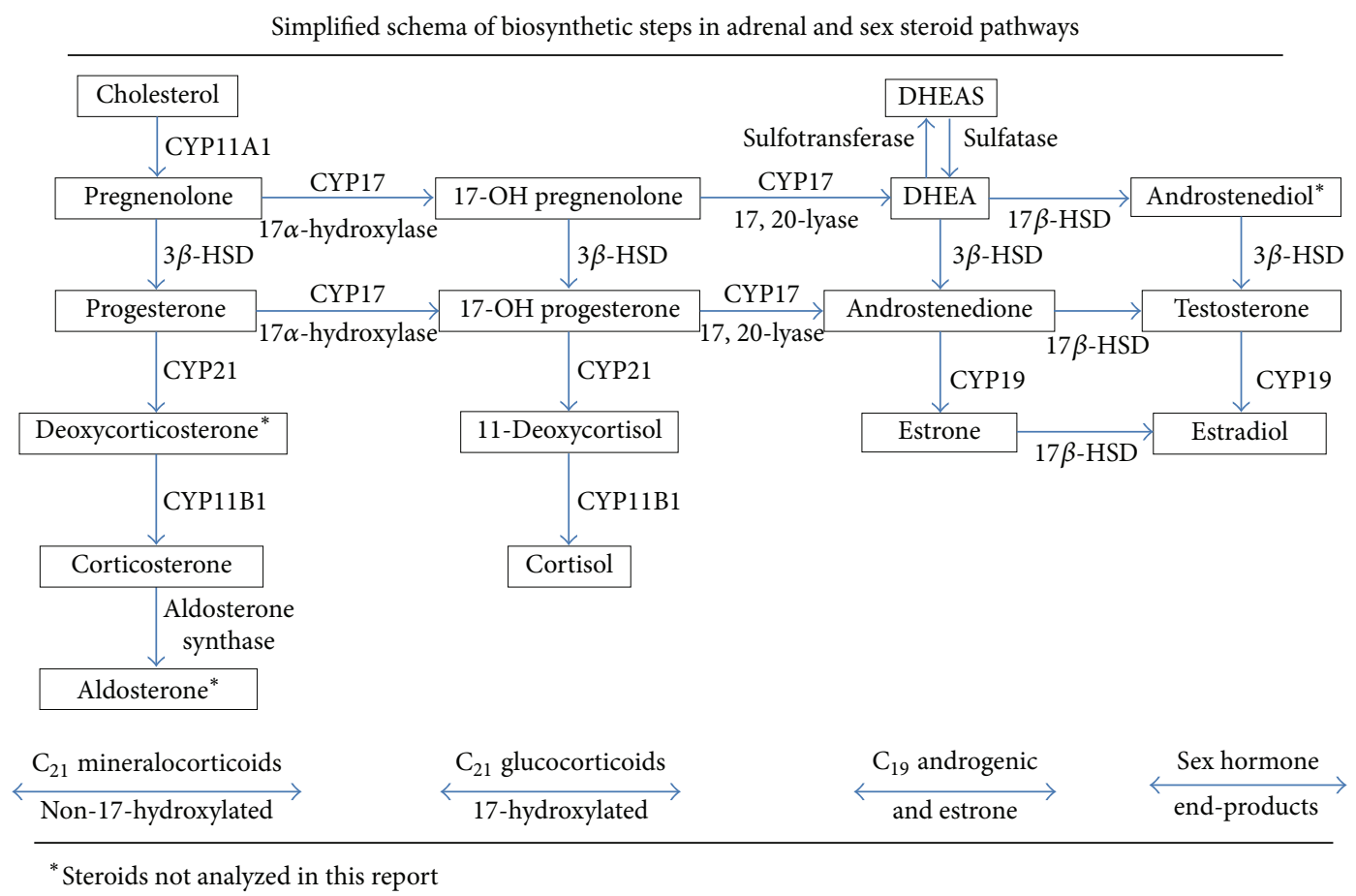

Figure 1: A simplified schema of the major adrenal and sex steroids, emphasizing the biosynthetic pathways leading to mineralocorticoids, glucocorticoids, adrenal androgens (AAs), and sex steroids. Initial conversion from cholesterol to pregnenolone is acutely controlled by ACTH, which chronically activates genes promoting other enzymes in the biosynthetic steps. The adrenal cortical volume increases during pre-pubertal adrenarche until young adulthood, particularly in the zona reticularis (ZR), along with its greater AA production, including DHEA, DHEAS, and androstenedione. Individual variability occurs in serum DHEAS levels, being lower in adult females than males, particularly after menopause (adrenopause). Serum AAs progressively decline with aging and are presumably accompanied by diminishing ZR mass. To the contrary, cortisol is derived from the zona fasciculata (ZF) and its levels remain stable over the ages, as does the ZF mass.

(Fraction B1). This fraction contained cortisol (F), deoxycortisol (DF), corticosterone (cmpd B), deoxycorticosterone (DOC), estrone (E1), and estradiol (E2). The third fraction was eluted with $12 \mathrm{~mL}$ of methanol: water: acetonitrile $(55: 35: 10)$. It contained androstenedione $(\triangle 4 \mathrm{~A})$, dehydroepiandrosterone (DHEA), 17-hydroxyprogesterone (17OHprog), 17-hydroxypregnenolone (17-OHpreg), and testosterone (T) (Fraction C1). The fourth fraction was eluted with $12 \mathrm{~mL}$ of methanol and it contained progesterone (prog) and pregnenolone (preg) (Fraction D1).

The aqueous component of each of the first two fractions was removed by adding an equal volume of water and transferring to a second ODS cartridge. The flow-through was discarded, and the steroids were then eluted with $5 \mathrm{~mL}$ of methanol. The solvents from all fractions were then evaporated under a stream of nitrogen in a water bath at $60^{\circ} \mathrm{C}$. The conjugated steroids in Fraction A1 were hydrolyzed by incubation with $10-12$ units of $\beta$-glucuronidase in $1.0 \mathrm{~mL}$ of $0.1 \mathrm{M}$ potassium phosphate buffer at $37^{\circ} \mathrm{C}$ for $18 \mathrm{hr}$. The now unconjugated androstanediol (adiol) and dehydroepiandrosterone (DHEA) were then extracted from the incubation mixture with ethyl ether (Fraction A2). The ethyl ether was then evaporated under a stream of nitrogen in a water bath at $60^{\circ} \mathrm{C}$.

The estrogens were separated from the neutral steroids in Fraction B1 by solvent partition between $0.4 \mathrm{M}$ aqueous $\mathrm{NaOH}$ and toluene. The aqueous fraction was neutralized by the addition of an equivalent amount of $\mathrm{HCl}$, and the estrogens were extracted from the neutralized aqueous solution with ethyl ether (Fraction B2). The toluene was evaporated from the neutral steroids and the ethyl ether was evaporated from the estrogen fraction (Fraction B3). Each of the steroids was later measured by radioimmunoassays with available antibodies and ${ }^{3} \mathrm{H}$-steroids from New England Nuclear Corp, Newton, MA.

The biologically active fraction of total serum cortisol is free cortisol, but that assay is technically demanding, expensive, and not in general use. Total cortisol is bound to plasma proteins, particularly corticosteroid-binding-globulin (CBG) or sex hormone binding globulin (SHBG), hepatic proteins having estrogen-induced increased synthesis. Intra-assay percentile coefficients of variation (\% CV) were all less than $12 \%$, as the criterion for acceptability of measurement results. Too few batches of assays were performed in either of the 1992 or 1994 sets to analyze their interassay variability. The fractionation procedure permitted steroid differentiation as did the antibody specificity incorporated in the assays.

2.4. Statistical Methods. Frequency distributions of the hormonal values were examined for acceptability of unimodality and symmetry features. Extreme outliers were observed in several hormones, particularly progesterone, as expected by physiological peaks during the luteal phase, and the opposite 
near-zero values during the postmenopausal status. Several extreme high outliers were also found in estradiol, which were attributed to ovulatory surges. Extreme outliers were assigned to the upper ranges observed in the population frequency distribution curves, thereby diminishing their statistical influence [26]. Differences in mean values of assayed steroids between the first (1992) and second (1994) sets were normalized, usually adjusting from the smaller first set mean to the larger second set mean, but reversed for $\triangle 4 \mathrm{~A}$, corticosterone, deoxycortisol, and DHEAS, in order to eliminate negative normalized values. Natural log conversion was performed on all values to improve their symmetry. Age-adjusted bivariate correlations (Pearson) of the individual steroids were performed on the normalized and logconverted values. These values were further transformed into $z$-scores to reduce their variances (1) in performing $t$-test differences of hormonal levels between subject groups and data subsets, and (2) in scatterplot examinations and confirmations of the data. The $z$-score values of the total normalized subjects centered on 0.00 standard deviations (SDs) and were almost always distributed between \pm 2 or \pm 3 SDs. The Fisher $r$-to- $z$ transformation was used to estimate significance of differences between two hormonal correlation coefficients in comparisons of total pre-RA versus $\mathrm{CN}$ as well as for subjects with lower than grand mean versus higher than grand mean baseline cortisol levels. When a significant difference was found in bivariate correlations between study groups and subgroups, a further correlational analysis was performed using set-specific $z$-scores of the respective reported assays in 1992 and 1994. When both analytical methods revealed significant $(P \leq 0.05)$ differences in correlations, those findings were indicated in the tables. A tentative illustrative model of adrenal glucocorticoid and androgenic anabolic (AA) steroid interrelations was inferred from hormonal differences observed between the total, lower, and higher cortisol subsets. In this exploratory study, a significance level of $P \leq 0.050$ was accepted without adjustment for multiple comparisons [27].

\section{Results and Discussion}

3.1. Differences in Reported and Normalized Steroids in Pre-RA and CN (Tables 1 and 2). The mean values of the normalized hormone assays (combining 1992 and 1994) for the total pre$\mathrm{RA}$ and $\mathrm{CN}$ subjects were similar, except for androstenedione $(\triangle 4 \mathrm{~A})$, which was lower $(P=0.018)$ in the 28 cases $(6.4 \pm 0.40)$ than the $108 \mathrm{CN}(7.8 \pm 0.28)$ (Table 1$)$. The first set (1992) preRA females contributed mainly to that difference; 5 of those 12 earlier tested cases had $\Delta 4 \mathrm{~A}$ levels of $-1 \mathrm{SD}$ or lower than the total subjects' mean level, compared to 1 of the 16 pre-RA tested in the second set $(P=0.057)$. The lower $\Delta 4 \mathrm{~A}$ levels were independent of baseline age, RA onset age, or interval in years from cohort entry to RA onset.

Our recent report [15] indicated that $4(11.1 \%)$ of the 36 pre-RA females versus $1(0.70 \%)$ of the $143 \mathrm{CN}$ had definitely low baseline cortisol levels ( $<55 \mathrm{nmol} / \mathrm{L}, P=0.006)$. Accordingly, further analysis was performed on the study subjects stratified into subgroups of lower $(<0.00 \mathrm{SD}$ grand mean $z$ scores) versus higher ( $0.00 \mathrm{SD}$ or greater) mean cortisol levels of the total 180 females, both subsets having similar mean ages
(Table 2). Again, the mean $\triangle 4 \mathrm{~A}$ level was lower in the pre-RA versus $C N$, but significant $(P=0.013)$ only in the subset of 9 pre-RA versus $53 \mathrm{CN}$ with lower mean cortisol levels (5.6 \pm 0.73 versus $8.0 \pm 0.42 \mathrm{nmol} / \mathrm{L}$, resp.). The mean DHEA level was not significantly $(P=0.133)$ lower in 10 pre-RA versus $52 \mathrm{CN}$ having lower mean cortisol levels (14.0 \pm 1.06 versus $19.8 \pm 1.88$, resp.). However, all cases had a negative $z$-score value of $<0.00$ SD versus $27(51.9 \%)$ of $52 \mathrm{CN}(P=0.004)$. This findings supports a previous report [8] of a greater $(P=$ 0.017 ) proportion of 15 premenopausal RA patients having combined lower DHEAS and cortisol levels than 14 matched control women ( $40 \%$ versus none). The total 12 pre-RA subjects with lower cortisol values in this study had a borderline $(P=0.058)$ lower baseline mean cortisol level than the comparator $72 \mathrm{CN}(102.5 \pm 14.7$ versus $145.0 \pm 5.72 \mathrm{nmol} / \mathrm{L}$, resp.).

The mean level of corticosterone (cmpd B), the complementary steroid in the mineralocorticoid pathway to cortisol (Figure 1), was significantly greater in subjects having higher versus lower grand mean cortisol levels, among the $\mathrm{CN}(P=0.001)$, pre-RA $(P=0.015)$, and total $(P<0.001)$ females (Table 2$)$. Further, the bivariate correlations of corticosterone and cortisol levels were significant in the total (Table 3) and higher-level cortisol (Table 5) pre-RA and CN subjects, as well as in the lower-level cortisol pre-RA cases (Table 4), implying that these hormone levels may reflect corresponding hypothalamic-pituitary ( $\mathrm{H}-\mathrm{P})$ activations. Without having the negative feedback control, as exists for cortisol, corticosterone production does respond to interval pulsatile activation of ACTH, and may be an approximate surrogate indicator of variations in $\mathrm{H}-\mathrm{P}$ stimulation of cortisol levels. The subject group with higher cortisol levels likely represents greater than average adrenal cortical ACTH activation, which is inferred from the conjointly higher levels of cortisol and its non-17hydroxylated comparable mineralocorticoid (Figure 1).

The mean estradiol (E2) concentration was greater $(P=$ 0.007 ) in the 18 pre-RA subjects who had a higher than grand mean cortisol level than their 50 comparator CN $(265 \pm 35$ versus $222 \pm 34 \mathrm{pmol} / \mathrm{L}$, resp.). As a complementary estrogenic finding, the 9 pre-RA who had higher cortisol levels had greater $(P=0.033)$ mean estrone (E1) levels than the 5 cases with lower cortisol (Table 2). Among the $\mathrm{CN}$ subjects, however, the mean E2 level was greater $(P=0.009)$ in those who had lower $(n=52)$ versus higher $(n=50)$ baseline mean cortisol levels (283 \pm 32 versus $222 \pm 34 \mathrm{pmol} / \mathrm{L}$, resp.).

3.2. Bivariate Correlations of Hormones in Total, Lower, and Higher Cortisol Pre-RA versus CN. The total female pre-RA (top) versus CN (bottom) age-adjusted, mean-normalized, and log-transformed bivariate correlations (Pearson) of the hormone profile are indicated in Table 3. In the $\mathrm{CN}$, as expected in normal physiology (Figure 1), pregnenolone, the initial steroid in the biosynthetic pathway, was strongly $(P<$ $0.001)$ correlated with its proximate products: progesterone, $17-\mathrm{OH}$ pregnenolone, and $17-\mathrm{OH}$ progesterone. However, pregnenolone was not correlated with the adrenal androgens (DHEA and $\triangle 4 \mathrm{~A}$ ), nor with cortisol. Rather, it was correlated with corticosterone $(P=0.005)$ and with deoxycortisol $(P=0.004)$. Of interest, pregnenolone was significantly 


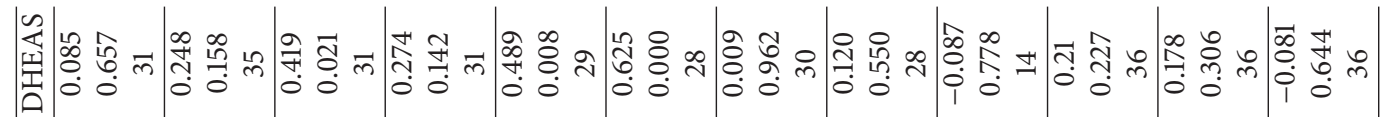

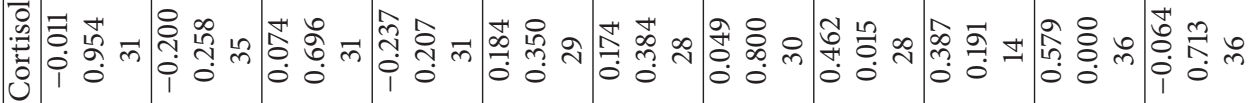

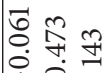

范。

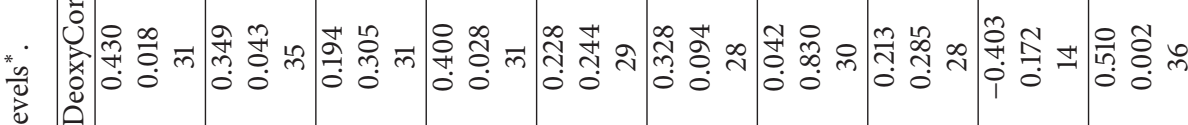

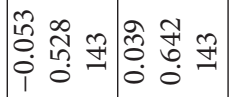

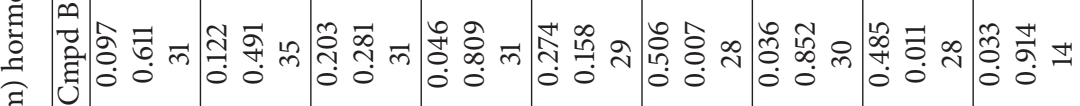

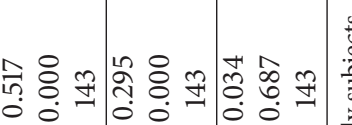

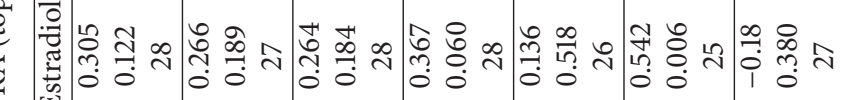

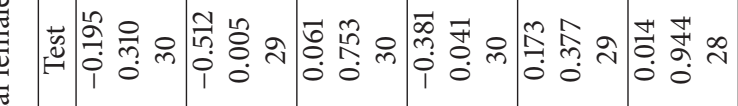

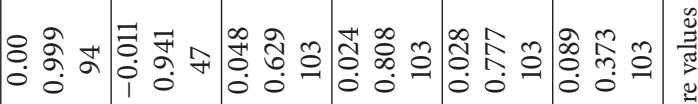

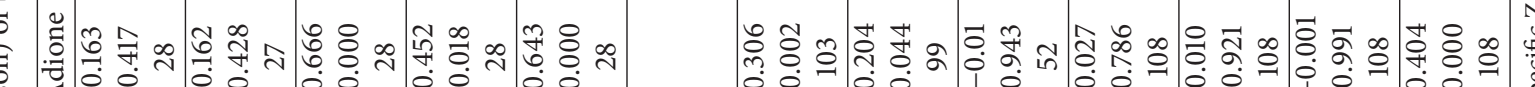

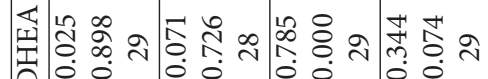

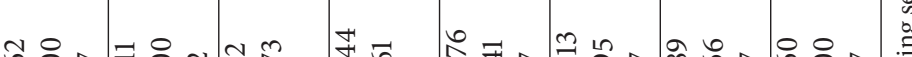

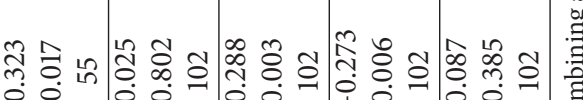

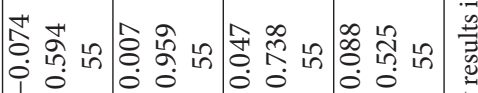

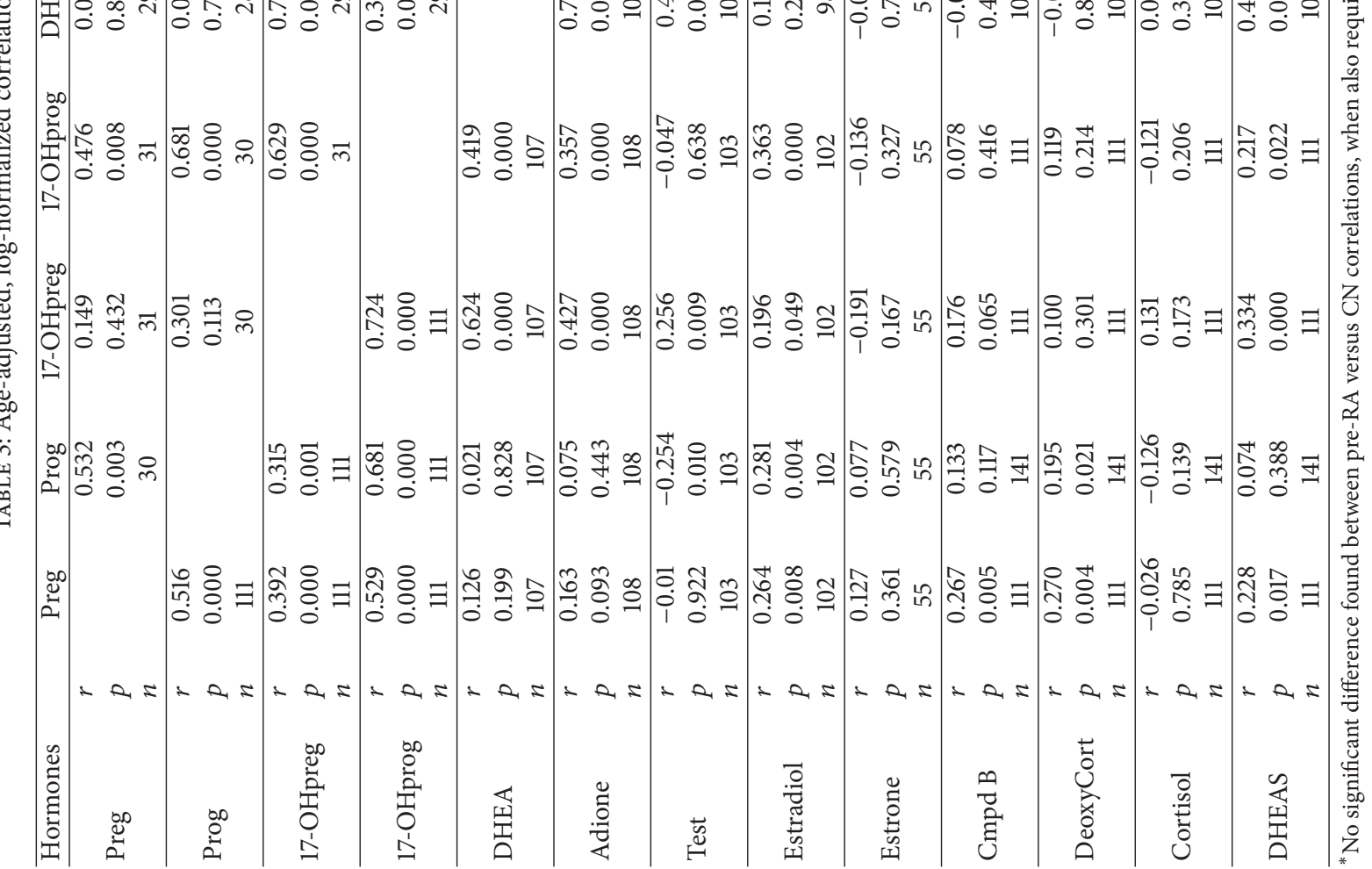




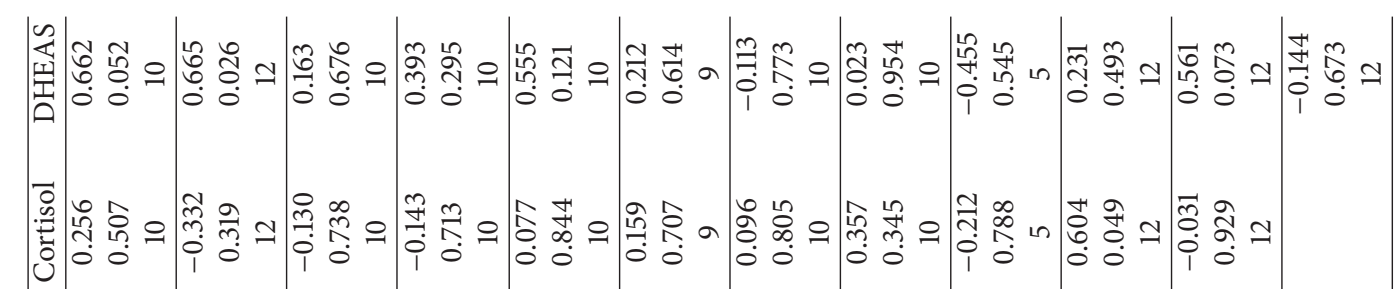

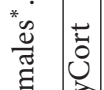

(1)

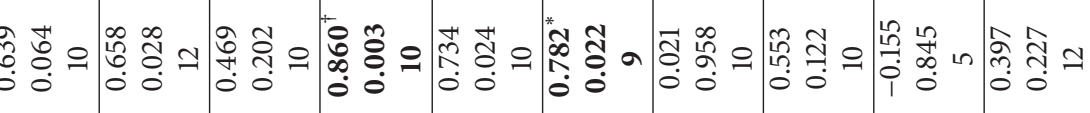

至

(1)

产

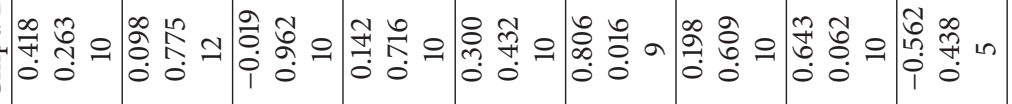

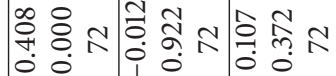

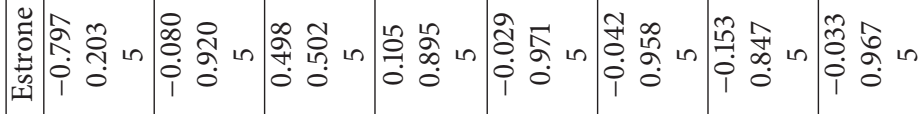

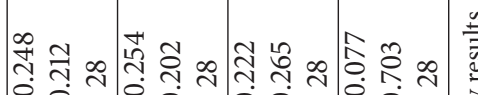

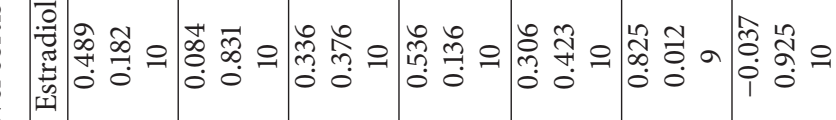

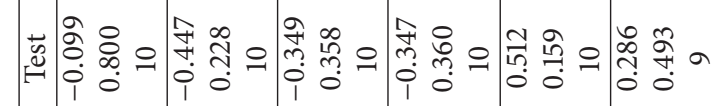

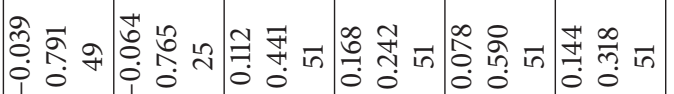

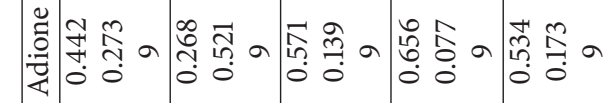

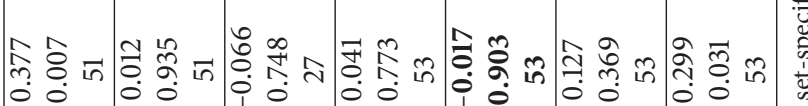

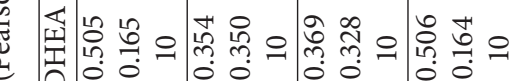

政

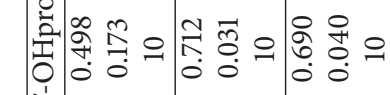

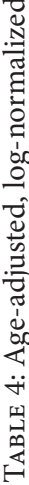

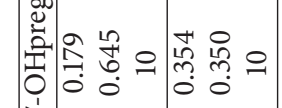

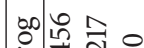

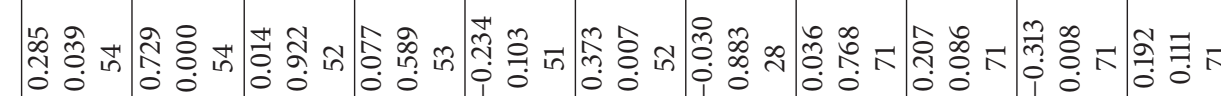

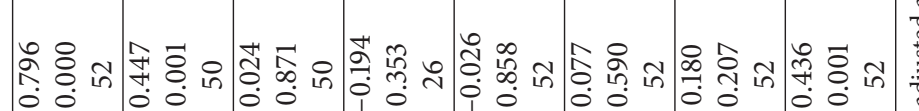

200

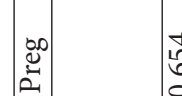

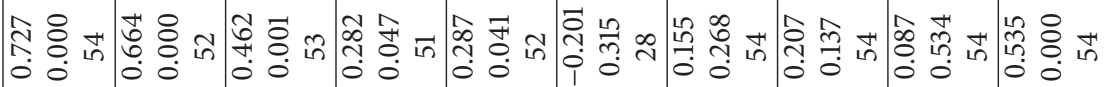

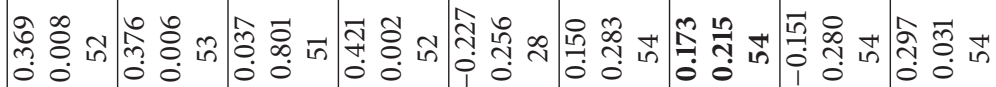

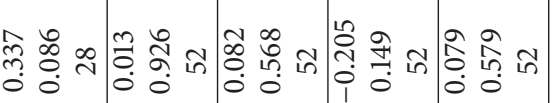

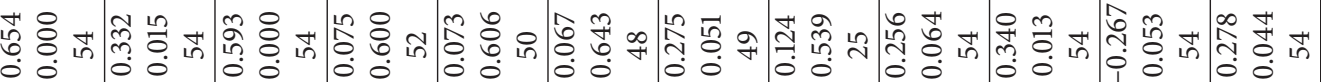

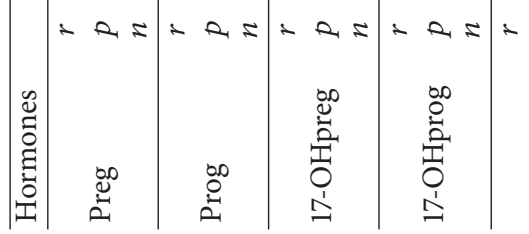
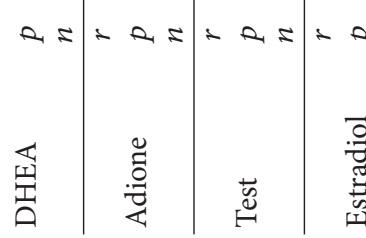

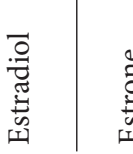

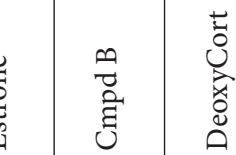

$\begin{array}{ll}5 & \\ 0 & 0 \\ 0 & 0 \\ 0 & 0 \\ 0 & 0\end{array}$

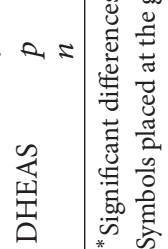




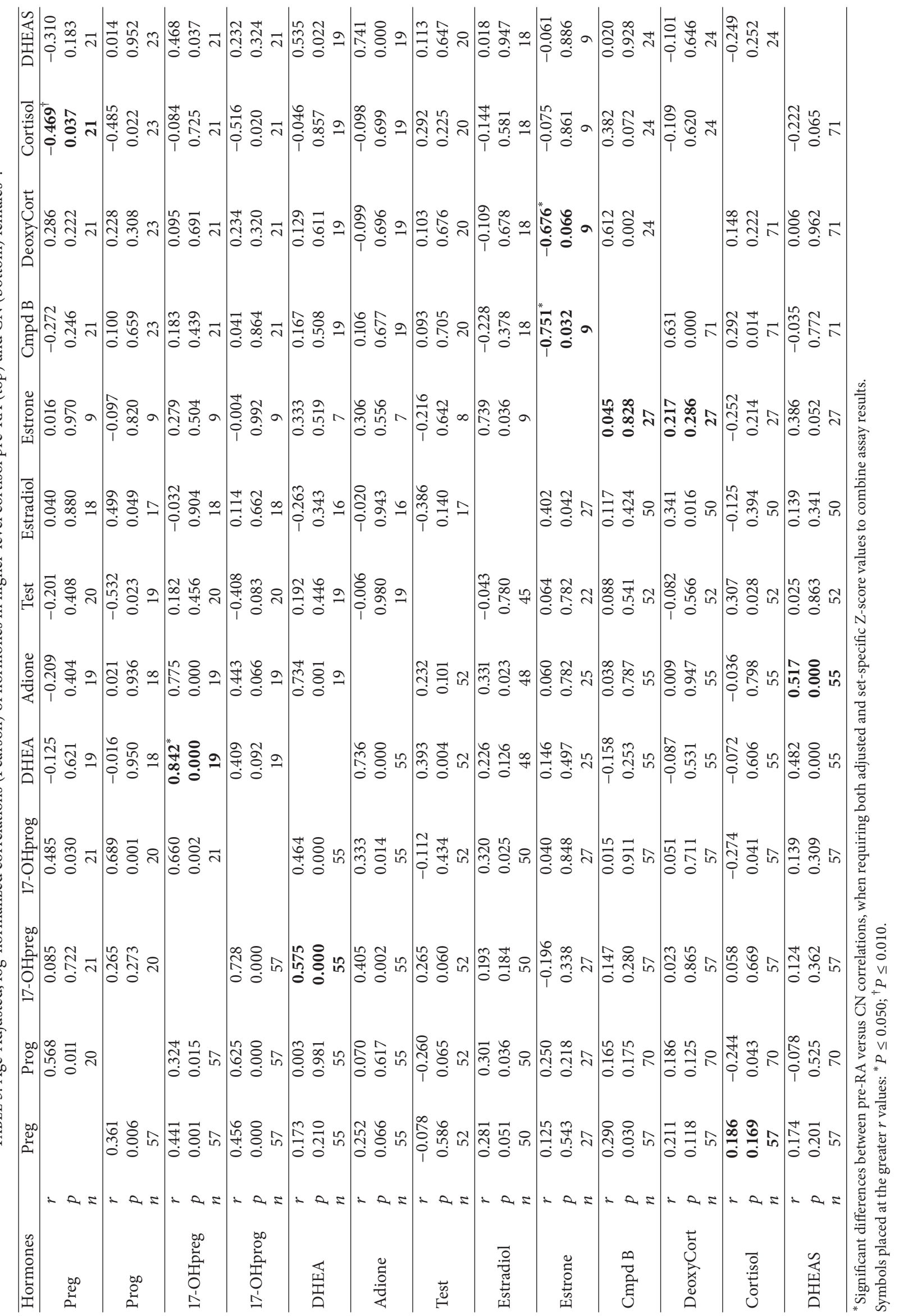


$(P=0.008)$ correlated with estradiol (E2). In the smaller pre-RA sample, pregnenolone was also correlated significantly with progesterone, $17-\mathrm{OH}$ progesterone, and deoxycortisol, but again, not with cortisol.

Regarding correlations of the adrenal androgens, DHEA, and $\triangle 4 \mathrm{~A}$, each was strongly correlated with the other and with their 17-hydroxylated precursors, $17-\mathrm{OH}$ pregnenolone and $17-\mathrm{OH}$ progesterone, in both the pre- $\mathrm{RA}$ and $\mathrm{CN}$ subjects (Table 3). These findings indicate that the $17 \alpha$-hydroxylase step is important in AA synthesis (Figure 1). The AAs were not correlated with the nonhydroxylated pregnenolone or progesterone enzymatic step precursors.

3.3. Similar Bivariate Correlations in the Total Pre-RA versus CN Subjects (Table 3). The bivariate hormonal correlations for total pre-RA (top) and CN (bottom) subjects were similar (Table 3). Cortisol and E2 were reported to have counteropposing effects on their alternate hypothalamic-pituitary (H-P) axis controls [17]. Cortisol and HPA axis stimulation tend to inhibit the HPG axis, whereas estrogen may stimulate the HPA axis and the peripheral production of cortisol [17].

3.4. Differences in Bivariate Correlations of Lower Cortisol Pre$R A$ versus CN Subjects (Table 4). In the lower cortisol subject groups (Table 4), expected physiological interrelations were again observed, as described above for the total subjects (Table 3). The bivariate correlations were again generally similar between subject groups, but with 2 differences (deltas). The pre-RA had significantly stronger correlations than the $\mathrm{CN}$ in deoxycortisol with $17-\mathrm{OH}$ progesterone $(r=0.860$, $P=0.003, n=10$ versus $r=0.173, P=0.215, n=54$, resp., delta $P=0.008)$ and with $\Delta 4 \mathrm{~A}(r=0.782, P=0.022, n=9$ versus $r=-0.017, P=0.903, n=53$, resp., delta $P=0.014$ ). Again, these study group correlational differences raise the issue of the degree of ACTH activation of the adrenal cortical pathways, feasibly being stronger in the lower cortisol pre-RA versus $\mathrm{CN}$ subjects (Figure 2).

3.5. Differences in Bivariate Correlations of Higher Cortisol Pre-RA versus CN Subjects (Table 5). Concerning the higher cortisol levels (Table 5), almost twice the number of preRA subjects were included than in the lower cortisol group (Table 4). Four low-level $(P \leq 0.050)$ significant differences were observed, including 3 pairs of hormonal correlations involving pregnenolone, 17-hydroxypregnenolone, and estrone (E1). In pre-RA, the pregnenolone correlation was negative with cortisol in pre-RA $(r=-0.469, P=0.037$, $n=21)$, but positive in the $\mathrm{CN}(r=0.186, P=0.169, n=$ $57)$, the difference being significant $(P=0.011)$. Regarding the hydroxylated precursor steroid, $17-\mathrm{OH}$ pregnenolone, the pre-RA had even stronger positive correlation with DHEA $(r=0.842, P<0.000, n=19)$ than did the $\mathrm{CN}(r=0.575$, $P<0.000, n=55)$, the difference also being significant $(P=$ 0.046 ) (Table 5). The stronger positive AA steroid correlation of DHEA with its precursor steroid, 17-OH pregnenolone, may imply that the observed relative deficiency of this AA had not likely resulted from a specific inhibition at the $17 \alpha$ hydroxylase step (Figure 1).
The correlations of estrone (E1) with both corticosterone and deoxycortisol were negative in pre-RA $(r=-0.751$ and $r=-0.676$, resp.), but positive in $\mathrm{CN}(r=0.045$ and $r=$ 0.217 , resp.), the differences being $P=0.025$ and $P=0.023$, respectively (Table 5$)$. The mean estrone level was greater $(P=0.033)$ in the pre-RA women with higher versus lower cortisol levels ( $265 \pm 44.3$ versus $127 \pm 27.3 \mathrm{pmol} / \mathrm{L}$, resp.), as indicated in Table 2.

3.6. Inferences from the Pre-RA versus $C N$ Hormonal Profile Mean Differences and Correlations. In the absence of quantitative measurements of the degree of ACTH, FSH, and LH end-organ stimulation (Figure 2), interpretation of the baseline serum adrenal and sex steroid profiles is challenging in the pre-RA versus CN subjects of this study as well as in previous comparisons of RA patients and controls $[4-8,12$, 28-32]. Adrenal cortical stimulation by the insulin-induced hypoglycemia test (IIHT) was studied in pre-menopausal RA patients and control females. One study [33] did not reveal a significant difference in cortisol response. The other study [8] revealed a baseline combined "lower" quartile range of serum cortisol and DHEAS levels including 6 of the 15 early RA patients, but none of $14 \mathrm{CN}(P=0.017)$. The finding suggested a relative hypocompetence of adrenal cortical function in some premenopausal RA females [8]. Few studies have measured ACTH, serum cortisol, or other steroid levels of RA patients without having glucocorticoid therapy at baseline measurements or after HPA axis stimulation [4, 12, 34-39]. Two studies $[34,36]$ showed significantly elevated ACTH levels without hypercortisolemia in untreated RA patients, but a difference was not found in the other studies. Lower DHEA levels in two of the above studies suggested decreased synthesis of AAs and deficient zona reticularis function in the $\mathrm{RA}$ versus $\mathrm{CN}[4,12]$.

To our knowledge, this is the first study of a comprehensive panel of adrenal and sex steroid levels in women prior to the onset of RA and matched cohort controls. The lower androstenedione level in the pre-RA occurred mainly in those subjects who also had lower cortisol levels than the grand mean of total subjects. In that lower-cortisol subgroup (Table 4), pre-RA had a stronger correlation of deoxycortisol with $\triangle 4 \mathrm{~A}$ than did the $\mathrm{CN}$. The preceding non-AA steroid level may be a surrogate indicator of ACTH stimulation, which is not directly regulated by the negative feedback mechanism controlling cortisol levels (Figure 2).

The lower AA levels in a minority of the pre-RA cases may likely reflect a lower AA synthesis capacity in those women, rather than lesser ACTH stimulation. Perhaps, such physiology may be analogous to natural processes in aging $[18,40,41]$ ? Figure 2 outlines an inductive model in which a minority subset of pre-RA women may have lower or relatively insufficient adrenal cortical functional capacity, rather than a deficit of hypothalamic-pituitary (H-P) stimulation or specific enzymatic defects [41-45]. The mechanisms for biological impairments of AA production are profoundly complex and are not yet fully defined but do occur in natural aging $[18,40,41]$. The biosynthetic mechanisms controlling AA synthesis and their levels during life cycles and between the genders remain unproved [41-45]. Further research is 


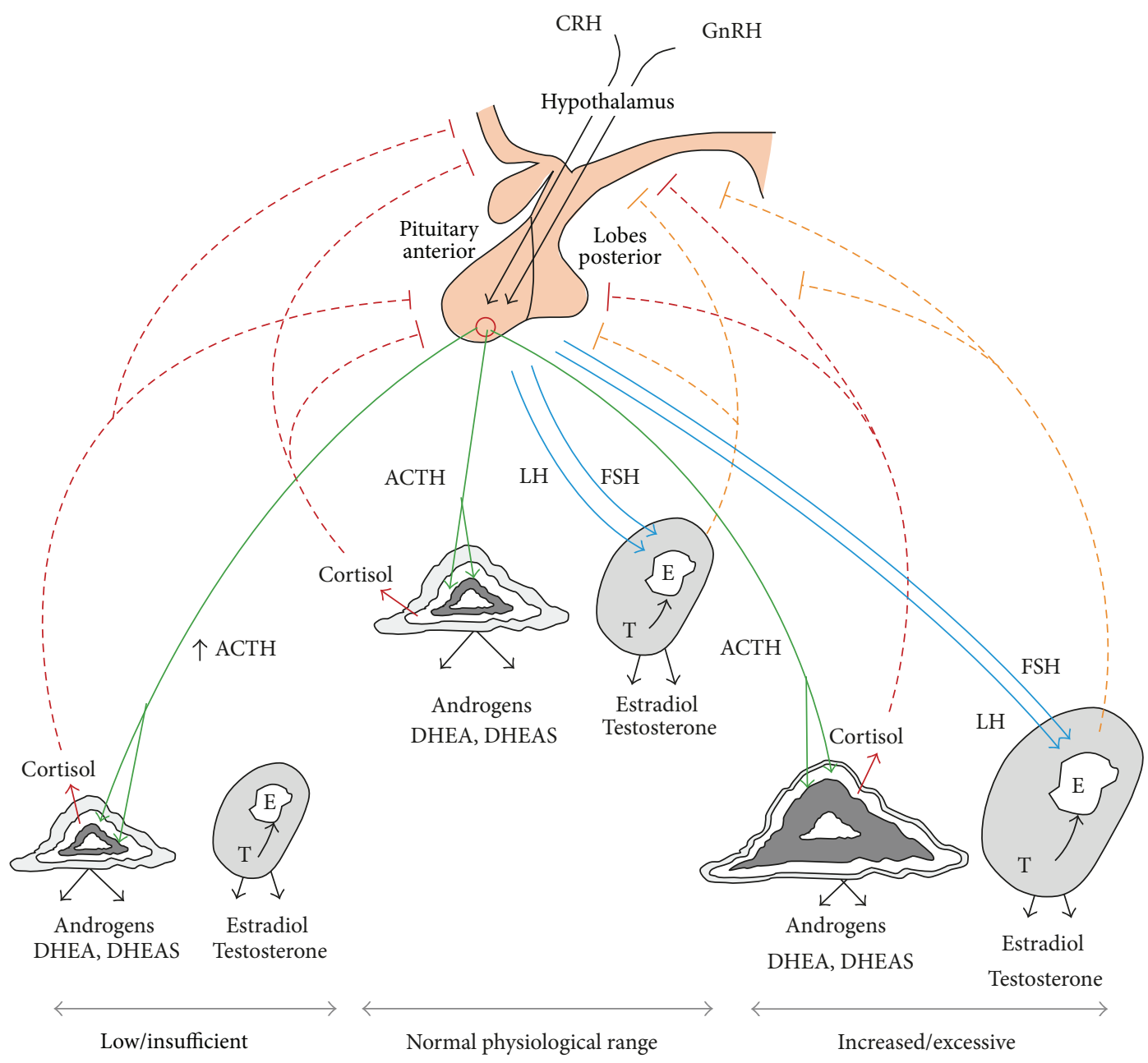

Inductive categories in the range of HPA and HPG hormonal variations

FIGURE 2: An inductive categorical schema of adrenal cortical and ovarian tropic (ACTH, LH, and FSH) and trophic (steroidogenic cell mass or competency) influences on cortisol, adrenal androgen (AA), and sex hormone production, in relation to AA status in females. Negative feedback control of the hypothalamic-pituitary-adrenal (HPA) and ovarian (HPG) axes is illustrated. Solid lines indicate stimulation and dashed lines indicate inhibition, within the respective systems. Direct and indirect interactions between the respective HPA and HPG axes are not illustrated. The HPA axis can inhibit the HPG axis at multiple levels and estrogen may stimulate the HPA axis [17]. The enlarged ovary model portrays tropic (LH, FSH) and trophic mechanisms operating in polycystic ovarian syndrome (PCOS), rather than a normally large gland. The adrenal cortex and ovary are derived from a common embryonic anlage. It is not known if trophic influences can cause an "enlarged adrenal organ syndrome," analogous to PCOS. Regarding low adrenal and low ovarian gland sizes, defined syndromes are also not documented, but individual variation and diminishing size occur in natural aging. Cortisol is synthesized mainly in the zona fasciculata (ZF, white area), which has the largest mass of the adrenal cortex (circa 70\%). The AAs, DHEA and androstenedione, are mainly produced in the zona reticularis (ZR, darker grey area), which has the smallest mass (circa 10\%). In females, the AAs are the major source of androgenic compounds. The mineralocorticoids are synthesized in the outermost zona glomerulosa (ZG, light gray area), which has a medium mass (circa 20\%) of the adrenal cortex. Cortisol and AA production are stimulated by ACTH secretion in a pulsatile pattern under regulation of the hypothalamic-pituitary (H-P) axis. Cortisol, in turn, inhibits the H-P in a negative feedback manner. It directly suppresses hypothalamic corticotropin releasing hormone (CRH) and its action on the pituitary secretion of ACTH. Insufficiency of cortisol leads to less inhibition of the CRH-ACTH axis and to increased ACTH. In normal aging, cortisol levels are fully maintained in the setting of decreased AA production and associated decreased ZR mass. The overall size of the adrenal cortex is stable in aging, but the outer cortical zones (ZG and ZF) are relatively increased in size to the diminished ZR [18]. The ovarian AA steroids are androstenedione mainly and testosterone (T), which lack negative feedback inhibition at the H-P levels, a function accomplished by estrogen (E).

required to confirm the observed relative AA insufficiency in a minority subset of women before onset of RA as well as the differences found in hormonal correlations. If these findings are confirmed, they will need to be defined in terms of their biosynthetic and control mechanisms [18, 4045]. 


\section{Conclusions}

Serum androstenedione $(\Delta 4 \mathrm{~A})$ levels were lower in a cohort of pre-RA versus $\mathrm{CN}$ females, particularly among subjects who had lower than the total subjects' mean cortisol level (Tables 1 and 2). In pre-RA versus $\mathrm{CN}$ women having lower cortisol levels (Table 4), stronger correlations of deoxycortisol with $17-\mathrm{OH}$ progesterone and with $\Delta 4 \mathrm{~A}$ were found in the cases, suggesting that those subjects had sufficient or potentially increased ACTH stimulation. The pre-RA with higher cortisol levels showed a stronger correlation of DHEA with its $17-\mathrm{OH}$ pregnenolone precursor than did the $\mathrm{CN}$ (Table 5). Accordingly, the AA deficiency does not seem likely based upon the respective enzymatic defect.

Multiple comparisons were performed in this study which could lead to an inflated rate of type I error, identifying low-level $(P \leq 0.050)$ differences which do not truly exist, and which require independent confirmation. Steroid interactions are part of complex homeostatic control mechanisms which tend to modulate deviations. In such systems, accumulated minor deviations in the same direction could be supportive of subtle dysfunctions, as is proposed. However, the observed differences were found only in a minority subgroup of pre-RA women versus $\mathrm{CN}$ women. Further investigation is needed of possible polymorphic variations diminishing cellular biosynthetic capacities of adrenal and ovarian steroids as a risk factor for RA in a subset of females (Figure 2).

\section{Conflict of Interests}

The authors declare that they have no conflict of interests.

\section{Acknowledgments}

The CLUE study, Campaign Against Cancer and Stroke, was funded in 1974 by Grant CA 11849 from the National Cancer Institute. The authors thank Mary Jean Dzursin for artistic expertise in helping to finalize the figure on categories of hormonal variation. The Research Open Access Publishing (ROAAP) Fund of the University of Illinois at Chicago provided the financial support towards the open access publishing fee for this paper. Support for this project was provided by the Department of Medicine, University of Illinois College of Medicine at Peoria, and by a gift from The MTM Foundation, with no existing or potential conflict of interests.

\section{References}

[1] A. T. Masi and G. P. Chrousos, "Hypothalamic-pituitaryadrenal-glucocorticoid axis function in rheumatoid arthritis," The Journal of Rheumatology, vol. 23, no. 4, pp. 577-581, 1996.

[2] R. L. Wilder, "Adrenal and gonadal steroid hormone deficiency in the pathogenesis of rheumatoid arthritis," The Journal of Rheumatology, vol. 44, pp. 10-12, 1996.

[3] R. L. Wilder and I. J. Elenkov, "Hormonal regulation of tumor necrosis factor- $\alpha$, interleukin-12 and interleukin-10 production by activated macrophages. A disease-modifying mechanism in rheumatoid arthritis and systemic lupus erythematosus?"
Annals of the New York Academy of Sciences, vol. 876, pp. 1431, 1999.

[4] K. S. Kanik, G. P. Chrousos, H. R. Schumacher, M. L. Crane, C. H. Yarboro, and R. L. Wilder, "Adrenocorticotropin, glucocorticoid, and androgen secretion in patients with new onset synovitis/rheumatoid arthritis: relations with indices of inflammation," Journal of Clinical Endocrinology and Metabolism, vol. 85, no. 4, pp. 1461-1466, 2000.

[5] M. Cutolo, L. Foppiani, and F. Minuto, "Hypothalamic-pituitary-adrenal axis impairment in the pathogenesis of rheumatoid arthritis and polymyalgia rheumatica, Journal of endocrinological investigation, vol. 25, no. 10, pp. 19-23, 2002.

[6] R. H. Straub, L. Paimela, R. Peltomaa, J. Schölmerich, and M. Leirisalo-Repo, "Inadequately low serum levels of steroid hormones in relation to interleukin- 6 and tumor necrosis factor in untreated patients with early rheumatoid arthritis and reactive arthritis," Arthritis and Rheumatism, vol. 46, no. 3, pp. 654-662, 2002.

[7] A. T. Masi, J. C. Aldag, and R. T. Chatterton, "Sex hormones and risks of rheumatoid arthritis and developmental or environmental influences," Annals of the New York Academy of Sciences, vol. 1069, pp. 223-235, 2006.

[8] R. Imrich, M. Vigas, J. Rovensky, J. C. Aldag, and A. T. Masi, "Adrenal plasma steroid relations in glucocorticoidnaïve premenopausal rheumatoid arthritis patients during insulininduced hypoglycemia test compared to matched normal control females," Endocrine Regulations, vol. 43, no. 2, pp. 65-73, 2009.

[9] A. T. Masi, "Incidence of rheumatoid arthritis: do the observed age-sex interaction patterns support a role of androgenic-anabolic steroid deficiency in its pathogenesis?" British Journal of Rheumatology, vol. 33, no. 8, pp. 697-699, 1994.

[10] M. Pikwer, U. Bergström, J. A. Nilsson, L. Jacobsson, and C. Turesson, "Early menopause is an independent predictor of rheumatoid arthritis," Annals of the Rheumatic Diseases, vol. 71, no. 3, pp. 378-381, 2012.

[11] A. T. Masi, D. B. Josipovic, and W. E. Jefferson, "Low adrenal androgenic-anabolic steroids in women with rheumatoid arthritis (RA): gas-liquid chromatographic studies of RA patients and matched normal control women indicating decreased 11-deoxy-17-ketosteroid excretion," Seminars in Arthritis and Rheumatism, vol. 14, no. 1, pp. 1-23, 1984.

[12] L. Foppiani, M. Cutolo, P. Sessarego et al., "Desmopressin and low-dose ACTH test in rheumatoid arthritis," European Journal of Endocrinology, vol. 138, no. 3, pp. 294-301, 1998.

[13] M. Cutolo, L. Foppiani, C. Prete et al., "Hypothalamic-pituitaryadrenocortical axis function in premenopausal women with rheumatoid arthritis not treated with glucocorticoids," The Journal of Rheumatology, vol. 26, no. 2, pp. 282-288, 1999.

[14] A. T. Masi, R. T. Chatterton, Y. C. Lu et al., "Low serum dehydroepiandrosterone sulfate (DHAS) levels, rheumatoid factor (RF) and elevated serum tumor necrosis factor $\alpha$ (TNF $\alpha)$ without cytokine receptor (CK) elevations predict long-term onset of RA in women: a controlled, prospective study," Arthritis \& Rheumatism, vol. 38, p. 214, 1995.

[15] A. T. Masi, K. B. Elmore, A. A. Rehman, J. C. Aldag, and R. T. Chatterton, "Pre-rheumatoid arthritis (pre-RA) subjects had a minority excess with clearly low serum cortisol levels and females had a lower mean androstenedione levels than control (CN) cohorts in analysis of a large panel of serum steroids and pituitary hormones," Arthritis \& Rheumatism, vol. 64, p. S27, 2012. 
[16] A. T. Masi, A. A. Rehman, K. B. Elmore, and J. C. Aldag, "Serum acute phase protein and inflammatory cytokine network correlations: comparison of a pre-rheumatoid arthritis and non-rheumatoid arthritis community cohort," Journal of Innate Immunity, vol. 5, no. 2, pp. 100-113, 2013.

[17] N. C. Vamvakopoulos and G. P. Chrousos, "Hormonal regulation of human corticotropin-releasing hormone gene expression: implications for the stress response and immune/inflammatory reaction," Endocrine Reviews, vol. 15, no. 4, pp. 409-420, 1994.

[18] C. R. Parker, R. L. Mixon, R. M. Brissie, and W. E. Grizzle, "Aging alters zonation in the adrenal cortex of men," Journal of Clinical Endocrinology and Metabolism, vol. 82, no. 11, pp. 3898-3901, 1997.

[19] K. J. Helzlsouer, A. J. Alberg, G. B. Gordon et al., "Serum gonadotropins and steroid hormones and the development of ovarian cancer," Journal of the American Medical Association, vol. 274, pp. 1926-1930, 1995.

[20] N. Rothman, K. P. Cantor, A. Blair et al., "A nested case-control study of non-Hodgkin lymphoma and serum organochlorine residues," The Lancet, vol. 350, no. 9073, pp. 240-244, 1997.

[21] A. J. Alberg, G. B. Gordon, S. C. Hoffman, G. W. Comstock, and K. J. Helzlsouer, "Serum dehydroepiandrosterone and dehydroepiandrosterone sulfate and the subsequent risk of developing colon cancer," Cancer Epidemiology Biomarkers and Prevention, vol. 9, no. 5, pp. 517-521, 2000.

[22] D. M. Gerlag, K. Raza, L. G. van Baarsen et al., "EULAR recommendations for terminology and research in individuals at risk of rheumatoid arthritis: report from the Study Group for Risk Factors for Rheumatoid Arthritis," Annals of the Rheumatic Diseases, vol. 71, no. 5, pp. 638-641, 2012.

[23] F. C. Arnett, S. M. Edworthy, D. A. Bloch et al., "The American Rheumatism Association 1987 revised criteria for the classification of rheumatoid arthritis," Arthritis \& Rheumatism, vol. 31, no. 3, pp. 315-324, 1988.

[24] K. T. Jørgensen, A. Wiik, M. Pedersen et al., "Cytokines, autoantibodies and viral antibodies in premorbid and postdiagnostic sera from patients with rheumatoid arthritis: case-control study nested in a cohort of Norwegian blood donors," Annals of the Rheumatic Diseases, vol. 67, no. 6, pp. 860-866, 2008.

[25] A. T. Masi, S. L. Feigenbaum, and R. T. Chatterton, "Hormonal and pregnancy relationships to rheumatoid arthritis: convergent effects with immunologic and microvascular systems," Seminars in Arthritis and Rheumatism, vol. 25, no. 1, pp. 1-27, 1995.

[26] W. J. Dixon and J. W. Tukey, "Approximate behavior of the distribution of Winsorized t (Trimming/Winsorization 2)," Technometrics, vol. 10, no. 1, pp. 83-98, 1968.

[27] K. J. Rothman, "No adjustments are needed for multiple comparisons," Epidemiology, vol. 1, no. 1, pp. 43-46, 1990.

[28] M. Cutolo, E. Balleari, M. Giusti, M. Monachesi, and S. Accardo, "Sex hormone status of male patients with rheumatoid arthritis: evidence of low serum concentrations of testosterone at baseline and after human chorionic gonadotropin stimulation," Arthritis and Rheumatism, vol. 31, no. 10, pp. 1314-1317, 1988.

[29] A. T. Masi, J. A. P. Da Silva, and M. Cutolo, "Perturbations of hypothalamic-pituitary-gonadal (HPG) axis and adrenal androgen (AA) functions in rheumatoid arthritis," Bailliere's Clinical Rheumatology, vol. 10, no. 2, pp. 295-332, 1996.

[30] A. T. Masi, R. T. Chatterton, and J. C. Aldag, "Perturbations of hypothalamic-pituitary-gonadal axis and adrenal androgen functions in rheumatoid arthritis: an odyssey of hormonal relationships to the disease," Annals of the New York Academy of Sciences, vol. 876, pp. 53-63, 1999.

[31] P. Härle, G. Pongratz, C. Weidler, R. Büttner, J. Schölmerich, and R. H. Straub, "Possible role of leptin in hypoandrogenicity in patients with systemic lupus erythematosus and rheumatoid arthritis," Annals of the Rheumatic Diseases, vol. 63, no. 7, pp. 809-816, 2004.

[32] R. Imrich, M. Vlcek, J. C. Aldag et al., "An endocrinologist's view on relative adrenocortical insufficiency in rheumatoid arthritis: annals of the New York Academy of Sciences," Annals of the New York Academy of Sciences, vol. 1193, pp. 134-138, 2010.

[33] M. A. Gutiérrez, M. E. García, J. A. Rodriguez et al., "Hypothalamic-pituitary-adrenal axis function in patients with active rheumatoid arthritis: a controlled study using insulin hypoglycemia stress test and prolactin stimulation," The Journal of Rheumatology, vol. 26, pp. 277-281, 1999.

[34] J. Hall, E. F. Morand, S. Medbak et al., "Abnormal hypothalamicpituitary-adrenal axis function in rheumatoid arthritis: effects of nonsteroidal antiinflammatory drugs and water immersion," Arthritis and Rheumatism, vol. 37, no. 8, pp. 1132-1137, 1994.

[35] C. Jorgensen, N. Bressot, C. Bologna, and J. Sany, "Dysregulation of the hypothalamo-pituitary axis in rheumatoid arthritis," The Journal of Rheumatology, vol. 22, no. 10, pp. 1829-1833, 1995.

[36] B. Gudbjörnsson, B. Skogseid, K. Öberg, L. Wide, and R. Hällgren, "Intact adrenocorticotropic hormone secretion but impaired cortisol response in patients with active rheumatoid arthritis. Effect of glucocorticoids," The Journal of Rheumatology, vol. 23, no. 4, pp. 596-602, 1996.

[37] E. Templ, M. Koeller, M. Riedl, O. Wagner, W. Graninger, and A. Luger, "Anterior pituitary function in patients with newly diagnosed rheumatoid arthritis," British Journal of Rheumatology, vol. 35, no. 4, pp. 350-356, 1996.

[38] L. J. Crofford, K. T. Kalogeras, G. Mastorakos et al., "Circadian relationships between interleukin (IL)-6 and hypothalamicpituitary-adrenal axis hormones: failure of IL-6 to cause sustained hypercortisolism in patients with early untreated rheumatoid arthritis," Journal of Clinical Endocrinology and Metabolism, vol. 82, no. 4, pp. 1279-1283, 1997.

[39] A. M. M. Eijsbouts, F. H. J. van den Hoogen, R. F. J. M. Laan, A. R. M. M. Hermus, F. C. G. J. Sweep, and L. B. A. van de Putte, "Hypothalamic-pituitary-adrenal axis activity in patients with rheumatoid arthritis," Clinical and Experimental Rheumatology, vol. 23, no. 5, pp. 658-664, 2005.

[40] C. C. Chen and C. R. Parker Jr., "Adrenal androgens and the immune system," Seminars in Reproductive Medicine, vol. 22, no. 4, pp. 369-377, 2004.

[41] P. J. Hornsby, "Aging of the human adrenal cortex," Science of Aging Knowledge Environment, vol. 2004, no. 35, p. re6, 2004.

[42] Y. Nakamura, H. X. Gang, T. Suzuki, H. Sasano, and W. E. Rainey, "Adrenal changes associated with adrenarche," Reviews in Endocrine and Metabolic Disorders, vol. 10, no. 1, pp. 19-26, 2009.

[43] P. J. Hornsby, "Adrenarche: a cell biological perspective," Journal of Endocrinology, vol. 214, pp. 113-119, 2012.

[44] W. L. Miller, "The syndrome of 17, 20 lyase deficiency," The Journal of Clinical Endocrinology \& Metabolism, vol. 97, no. 1, pp. 59-67, 2012.

[45] W. L. Miller, "P450 oxidoreductase deficiency: a disorder of steroidogenesis with multiple clinical manifestations," Science Signaling, vol. 23, no. 254, p. pt11, 2012. 


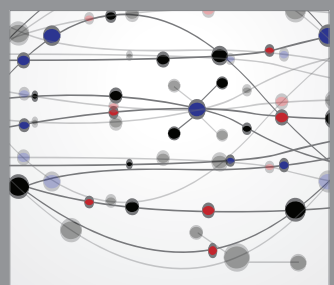

The Scientific World Journal
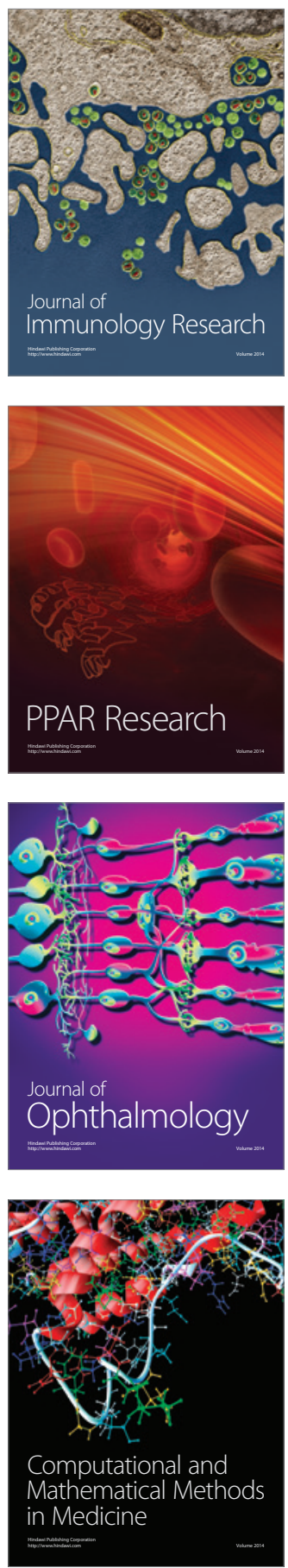

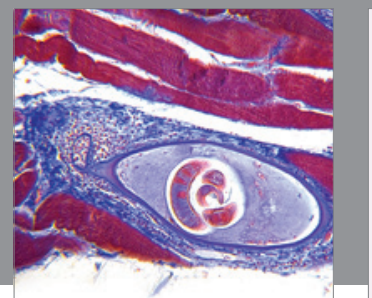

Gastroenterology

Research and Practice
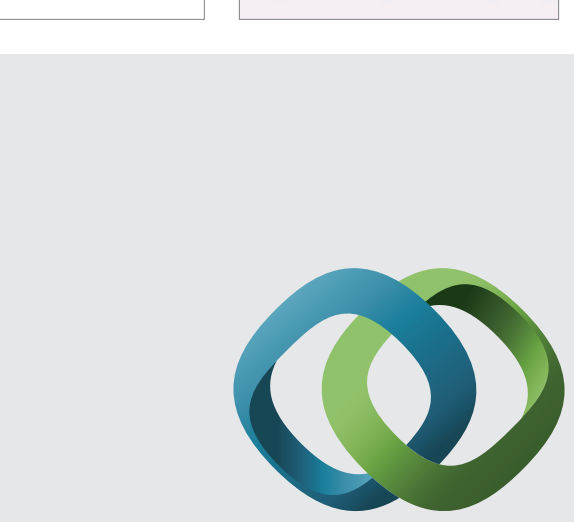

\section{Hindawi}

Submit your manuscripts at

http://www.hindawi.com
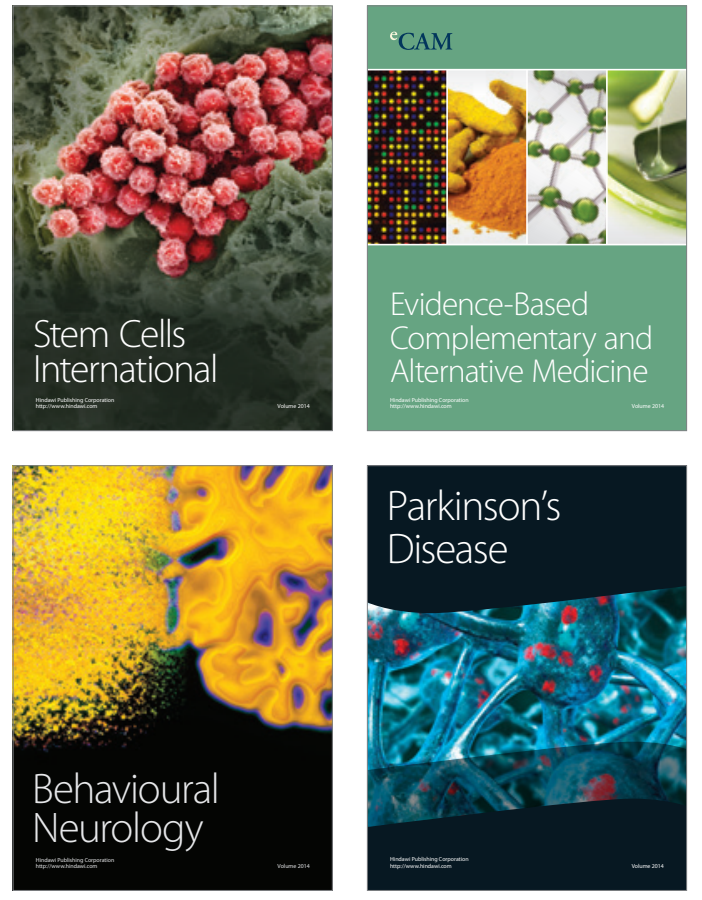
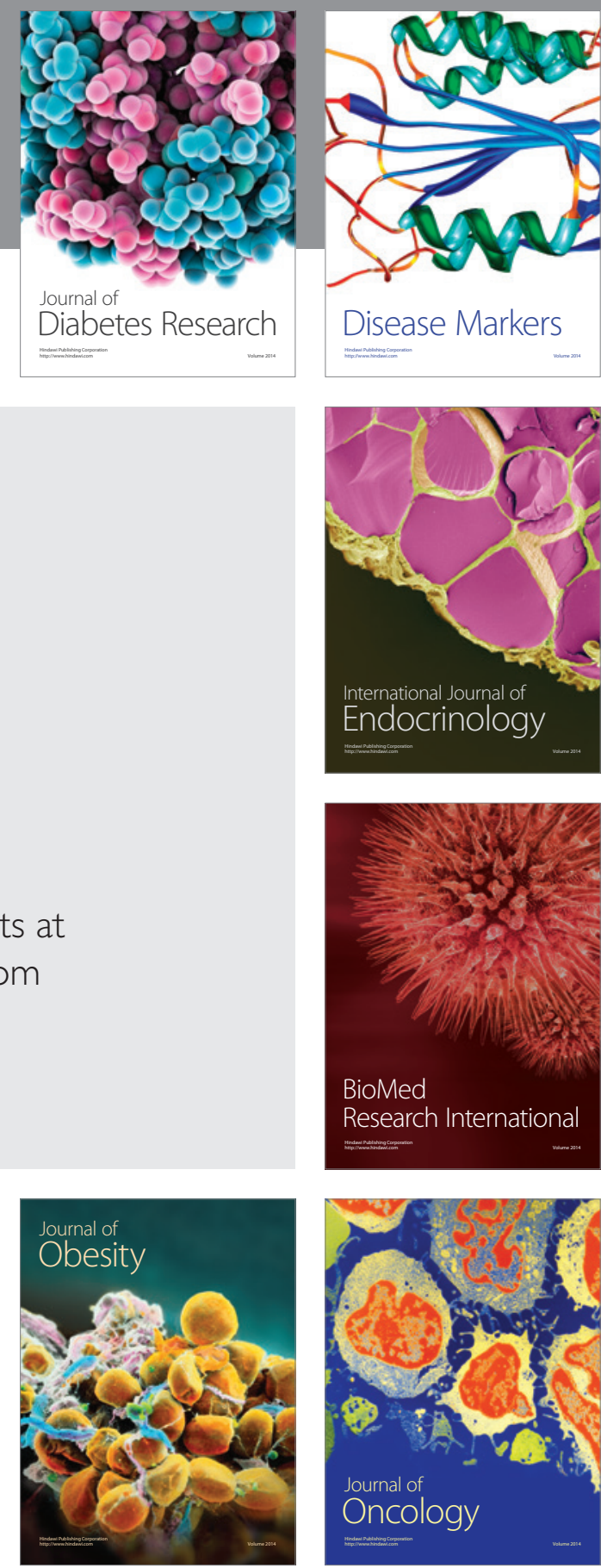

Disease Markers
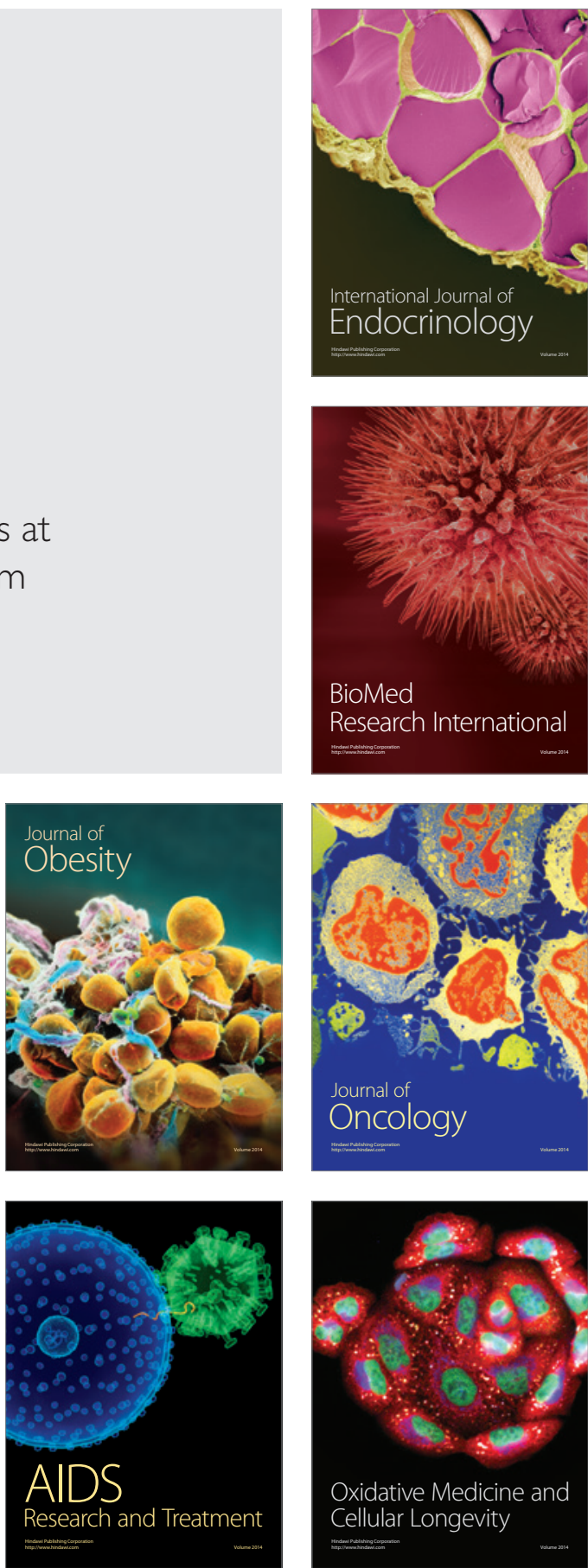